NBER WORKING PAPER SERIES

\title{
MEASURING THE GIG ECONOMY: CURRENT KNOWLEDGE AND OPEN ISSUES
}

\author{
Katharine G. Abraham \\ John C. Haltiwanger \\ Kristin Sandusky \\ James R. Spletzer \\ Working Paper 24950 \\ http://www.nber.org/papers/w24950 \\ NATIONAL BUREAU OF ECONOMIC RESEARCH
1050 Massachusetts Avenue
Cambridge, MA 02138
August 2018
}

John Haltiwanger was also a part-time Schedule A Employee of the U.S. Census Bureau at the time of the writing of this paper. Any opinions and conclusions expressed herein are those of the authors and do not necessarily represent the views of the U.S. Census Bureau or the National Bureau of Economic Research. All results have been reviewed to ensure that no confidential information is disclosed. We thank Joseph Altonji, Barry Bosworth, Carol Corrado, Susan Houseman, Ron Jarmin, Kristin McCue and participants in the CRIW Conference on Measuring and Accounting for Innovation in the 21 st Century for helpful comments and suggestions on an earlier draft.

NBER working papers are circulated for discussion and comment purposes. They have not been peer-reviewed or been subject to the review by the NBER Board of Directors that accompanies official NBER publications.

(C) 2018 by Katharine G. Abraham, John C. Haltiwanger, Kristin Sandusky, and James R. Spletzer. All rights reserved. Short sections of text, not to exceed two paragraphs, may be quoted without explicit permission provided that full credit, including $\odot$ notice, is given to the source. 
Measuring the Gig Economy: Current Knowledge and Open Issues

Katharine G. Abraham, John C. Haltiwanger, Kristin Sandusky, and James R. Spletzer

NBER Working Paper No. 24950

August 2018

JEL No. J40,J46

\begin{abstract}
$\underline{\text { ABSTRACT }}$
The rise of the "gig economy" has attracted wide attention from both scholars and the popular media. Much of this attention has been devoted to jobs mediated through various online platforms. While non-traditional work arrangements have been a perennial subject of debate and study, the perception that new technology is producing an accelerated pace of change in the organization of work has fueled a resurgence of interest in how such changes may be affecting both workers and firms. This paper provides a typology of work arrangements and reviews how different arrangements, and especially gig activity, are captured in existing data. A challenge for understanding recent trends is that household survey and administrative data paint a different picture, with the former showing little evidence of the growth in self-employment that would be implied by a surge in gig activity and the latter providing evidence of considerable recent growth. An examination of matched individual-level survey and administrative records shows that a large and growing fraction of those with self-employment activity in administrative data have no such activity recorded in household survey data. The share of those with self-employment activity in household survey data but not administrative data is smaller and has not grown. Promising avenues for improving the measurement of self-employment activity include the addition of more probing questions to household survey questionnaires and the development of integrated data sets that combine survey, administrative and, potentially, private data.
\end{abstract}

Katharine G. Abraham

Department of Economics and

Joint Program in Survey Methodology

University of Maryland

1218 LeFrak Hall

College Park, MD 20742

and NBER

kabraham@umd.edu

John C. Haltiwanger

Department of Economics

University of Maryland

College Park, MD 20742

and NBER

haltiwan@econ.umd.edu

\author{
Kristin Sandusky \\ Center for Economic Studies \\ U.S. Census Bureau \\ 4600 Silver Hill Road \\ Washington, DC 20233 \\ lee.k.sandusky@ census.gov \\ James R. Spletzer \\ Center for Economic Studies \\ U.S. Census Bureau \\ 4600 Silver Hill Road \\ Washington, DC 20233 \\ james.r.spletzer@census.gov
}




\section{Introduction}

In recent years, the popular press has been full of stories premised on the idea that the share of U.S. jobs that do not involve a formal employer-employee relationship is large and growing. Both media sources and scholars have adopted the term "gig economy” to refer broadly to these less structured work arrangements as well as more narrowly to the subset of flexible jobs mediated through various online platforms. The latter have been viewed as yielding an increasingly “on demand” economy where goods and services can be acquired through apps on smartphones and other web based applications. The current discussion regarding alternative work arrangements echoes an earlier discussion that arose in the late 1980s and 1990s (e.g., Abraham 1988, 1990; Barker and Christensen 1998). Then as now, there was talk of dramatic growth in the number of people working in contingent or precarious jobs - positions in which workers had no long-term connection to a particular business, but were employed to complete a specific task or for a defined period of time - or under other non-standard employment arrangements. The recent resurgence of interest in non-traditional work arrangements reflects the perception that new technology, along with the restructuring of business enterprises made possibly by this technology, is producing an accelerated pace of change in the organization of work that is having important effects on both workers and firms.

Much of the discussion of the gig economy, as well as the broader discussion of non-employee work arrangements, has focused on the implications of growth in these arrangements for workers and their families. On the one hand, gig work may appeal to individuals for whom it provides the flexibility to better match their skills to work projects. Making a similar point, Hurst and Pugsley (2011), for example, argue that self-employed workers enjoy substantial non-pecuniary benefits in the form of being their own boss, being able to set their own schedule and so on. On the other hand, some of those performing gig work are not doing so by choice. Similar to others who are not employees of the firms for which they are providing labor services, gig workers do not enjoy the legal rights and protections afforded under the unemployment insurance system, the workers compensation system, the Fair Labor Standards Act and other laws and regulations written with more traditional employment arrangements 
in mind (Harris and Krueger 2015). Further, those who rely primarily or exclusively on selfemployment are markedly less likely to have health insurance or to have a retirement plan (Jackson, Looney and Romnath 2017) and may have hours and earnings that are substantially more variable and less predictable.

Advances in technology resting on digitization and the inter-connectivity of the internet have made it increasingly attractive for firms to re-organize their activities so that a greater share of work is performed by individuals who are not employees of the firm. These new technologies make it more feasible to organize work on a project-specific basis, utilizing a changing cast of workers with the mix of skills that is appropriate for each project (National Academies Press 2017). Similar to the motivations that have been posited for other sorts of contracting out (Abraham and Taylor 1996; Dube and Kaplan 2010; Goldschmidt and Schmieder 2017), a shift from hiring workers into traditional employment relationships to utilizing non-employees as they are needed may be a means of reducing wage and benefit costs in addition to positioning the firm to respond quickly to shifts in demand. These same technological advances have facilitated the segmentation of the various aspects of firms' production processes more generally (see, e.g., Fort 2017). On the other hand, while offering some clear advantages to firms, increased reliance on outsourcing generally and non-employees specifically also implies less accumulation of firm-specific human capital. Even within narrowly defined sectors, there is enormous heterogeneity in the productivity and profitability of individual firms (see, e.g., Foster, Haltiwanger and Krizan 2001). Differences in the ability to attract, train and retain high quality workers, especially those performing functions that are core to the firm, seem likely to be an important contributor to this heterogeneity in firm-level outcomes.

Growth in non-employee work also matters for the measurement of economic activity. The current system of economic measurement is designed for a world in which workers have a traditional employment relationship or operate a formal business. Non-employee work may not be fully captured in existing data sources. Each month, for example, the Current Population Survey (CPS) collects information from households about work that household members have done for pay or profit. Similar to 
the questions asked on other household surveys, the CPS employment questions may not always cue respondents to report work outside of a conventional job or business and are not designed to probe regarding the nature of the arrangements under which work occurs. Further, they focus primarily on the main job a person holds, with a more limited set of questions asked about additional work activity. Other surveys collect information from businesses on the number of people they employ and the hours those employees work, but do not attempt to measure the labor input of people who are not on those businesses’ payrolls.

To the extent that an increasing share of the work embodied in firms’ products is supplied by non-employees whose hours are not well captured by existing data collections, measures of labor productivity growth may be distorted. Labor productivity is defined as output per hour worked. The Bureau of Labor Statistics (BLS) major sector productivity program uses CPS data to measure the hours of the self-employed. If there have been increases in non-employee work that are not well captured by the CPS, the growth in labor hours may have been understated and the growth in labor productivity correspondingly overstated. Further, if different sectors have made more or less intensive use of nonemployee labor input, the pattern of growth in productivity may have been distorted as well.

In principle, measures of multifactor productivity should take into account firms’ use of purchased services. Multifactor productivity is defined as output relative to an index of inputs to production, weighted according to their shares of production costs. So long as purchased services are well measured, changes in the amount of non-employee labor embedded in those services will be reflected in measured multifactor productivity. In practice, limited data on purchased services are collected and estimates of how the use of these services is allocated across industries may not be especially accurate. Houseman (2007), for example, cites evidence suggesting that estimates from the input-output tables used in the construction of industry productivity statistics significantly understated the growth in the use of staffing services in manufacturing during the 1990s. Similar problems may exist with respect to the measurement and allocation of labor services provided by non-employee workers. 
A somewhat different measurement problem may arise if non-employee workers sell services directly to consumers or produce tangible or intangible capital. In principle, one would like this output to be included in gross domestic product and incorporated into the measurement of productivity. Information on output is collected primarily through surveys and censuses of the employer businesses that account for the lion's share of production. In constructing its estimates of total output, the Bureau of Economic Analysis adjusts the figures for employer businesses using information on the revenues of non-employer businesses (Bureau of Economic Analysis 2017). Still, any failure of the existing measurement system to fully capture output for final demand that is produced by non-employee workers could be an additional source of distortion in measured trends in output and productivity.

While there has been considerable discussion about the changing nature of work and its broader implications for workers and firms, different sources of data send conflicting messages regarding the prevalence of non-employee work generally and gig employment specifically. Individuals performing non-employee work should be classified as self-employed. In the CPS and other household surveys, however, the percentage of the workforce that is self-employed has shown no upward trend and in fact has been drifting downwards since at least the mid-1990s. In contrast, administrative data derived from tax filings provide stronger support for the popular perception that non-employee work arrangements are a growing phenomenon (Katz and Krueger 2016).

Further, relatively little is known about the answers to other important questions about the gig economy. Who are the people engaged in gig work? Where are they working and what type of work are they doing? To what extent is gig work a primary source of earnings for those who do it as opposed to a source of supplementary income that complements earnings from a wage and salary job? Do those engaged in gig work tend to be low-earning or high-earning individuals? Where does such work fit into the life cycle career path of individuals? Do individuals engage in such work because they are pushed into doing it or do they do it by choice? Has any or all of this changed over time? What are the implications of any changes that have occurred for the measurement of output and productivity? 
In this paper, we seek to clarify what different sources of data can tell us about changes in the prevalence and nature of both gig employment and non-employee work arrangements more generally over time. We begin with a discussion in Section II of the heterogeneity of non-employee work and the challenges this heterogeneity poses to its measurement and assessment. Section III considers the two main types of data that have been used to study past trends in non-employee work - surveys of households and administrative data. The discrepancy between the flat or declining trend in self-employment shown by measures based on household surveys and the long term growth in similar measures based on administrative data is a significant puzzle. To reconcile these conflicting trends, we turn to analysis of a newly-created linked data file that contains household survey and administrative information based on tax records for the same individuals. Preliminary findings based on this linked file are reported in Section IV. Although there is some CPS self-employment for which we can find no corresponding tax records, the amount of such undocumented self-employment has been relatively stable; in contrast, there has been a notable increase in the volume of self-employment activity reported to the Internal Revenue Service (IRS) that is not reported on the CPS. Looking to the future, Section V considers ways in which household survey data on non-traditional employment might be improved and Section VI evaluates how employer survey data, tax data and naturally occurring private sector data might be used more effectively to improve our understanding of gig employment specifically and non-employee work more generally. Finally, Section VII offers some initial thoughts about a path forward. Recognizing the limitations of each of the individual available sources of data, efforts to develop linked data sets that combine household survey data, tax data, employer survey data and, potentially, naturally occurring private sector data are likely to have a high payoff, permitting greater insight into the changing nature of work than is possible using any single data source.

\section{Typology of Work Arrangements}

Although there has been a great deal of interest in the growth in non-traditional work arrangements in the U.S. labor market, discussion of these arrangements has not always fully recognized their considerable 
heterogeneity. Combining arrangements with very different characteristics and then attempting to generalize about them runs the risk of being quite misleading. Table 1 lays out a typology that attempts to clarify similarities and differences across a variety of ways of organizing work, separated broadly into employee and self-employment arrangements. The table also identifies where these arrangements might be captured in household survey and administrative data, as well as where gig employment specifically might be counted.

\section{Work Arrangements and Their Characteristics}

One challenge in characterizing the evolution of work arrangements is that there are many different ways to organize work. The first column of Table 1 lists a number of work arrangements that have been discussed in the literature. The categories listed in the table are not necessarily mutually exclusive and, in some cases, a job might fall into more than one category. In addition, any given person may have multiple jobs and work under multiple arrangements. The next five columns of the table identify some key dimensions along which the listed work arrangements may differ.

Despite ongoing changes in the labor market, traditional employment still accounts for the largest share of work in the U.S. labor market. These are jobs on which a worker is paid a wage or salary; has some expectation of job security; may be full-time or part-time, but has hours and earnings that are reasonably predictable; and is supervised by the same firm that pays her wage or salary. On-call workers and other direct-hire workers with varying schedules also appear on the payroll of the firm where they are employed, but their hours change depending on the needs of the firm and there may be periods when they do not work at all. A direct-hire temporary worker is someone who is employed for a limited term. Direct hire temporaries include seasonal employees such as lifeguards hired for the summer or sales clerks hired for the busy winter holiday season. ${ }^{1}$

An alternative to using workers hired directly onto a firm's own payroll is to use contract company workers on either a short-term or long-term basis. Temporary help agencies supply labor to businesses with intermittent, seasonal or other temporary demands for labor; professional employer

\footnotetext{
${ }^{1}$ Interestingly, the share of jobs that are seasonal has dropped significantly in recent decades (Hyatt and Spletzer 2017).
} 
organizations (PEOs) provide workers or services on a more permanent basis; and other contract firms may provide specific services on either a short-term or a long-term basis. Individuals in these arrangements are employees, but the firm on whose behalf work is being performed (the client) is a different entity than the firm writing the worker's paycheck (the agency, PEO or other contract firm).

As among employee arrangements, there is considerable diversity among the various categories of self-employment. The self-employed include business owners who may have a well-established clientele and a relatively predictable flow of work. Such businesses may be incorporated, organized as partnerships or operated as unincorporated sole proprietorships. The self-employed also include independent contractors or freelancers who earn money by performing one-off tasks for which they are paid an agreed sum. Such workers may not be able to count on steady work and their hours and earnings may be volatile. ${ }^{2} \mathrm{~A}$ day laborer is a person who gets work by waiting at a place where employers pick up people to help with short-term tasks. In some communities, for example, individuals seeking work may be known to wait in a convenience store parking lot or similar location. On-demand or platform workers can be thought of as the modern version of a day laborer, but with work obtained by claiming tasks listed through an online intermediary rather than by waiting for work at a physical location. Examples of the increasing number of on-line platforms that facilitate the matching of workers to those requiring services include Uber, TaskRabbit, Mechanical Turk and Upwork.

The first characteristic we have identified as relevant to distinguishing among the various work arrangements is simply whether the person is paid a wage or salary. This can be thought of as a shorthand for whether those working under the arrangement are likely to be covered by unemployment insurance, workers compensation, the Fair Labor Standards Act, and other labor market laws and regulations that are applicable to employees but generally not to those who are self-employed. ${ }^{3}$

\footnotetext{
${ }^{2}$ Independent contractors and freelancers could be folded into the unincorporated sole proprietor category, but some of those who would describe themselves as an independent contractor or freelancer may not think of themselves as operating a business.

3 The application of these laws and regulations to the owners of incorporated businesses who pay themselves a wage or salary is complicated, but in many states business owners are permitted to opt in to coverage under the unemployment insurance and workers compensation systems.
} 
A second important characteristic of a work arrangement is whether the work relationship can be expected to continue. This construct has been used by the BLS as the basis of its definition of contingent work (Polivka 1996a). In published BLS statistics from the Contingent Worker Supplement to the CPS, a contingent worker is anyone for whom no implicit or explicit contract for a continuing work relationship exists. Most traditional employees would not view their employment as contingent, but for consistency with how the BLS has applied this concept, we have allowed for the possibility that someone in such a position might consider their job to be time-limited because they expect the business where they work to close or their position to be eliminated. Accordingly, we have entered "some" rather than "yes" for traditional employees in the column summarizing whether a continuing work arrangement exists. Someone who works only when called in or who has a varying schedule may nonetheless have an ongoing relationship with the firm at which they work. Workers supplied by a temporary help agency or other contract firm may have only a short-term relationship with the different firms that make use of their services, but a continuing relationship with the temporary help agency or contract firm. In contrast, we would not expect direct-hire temporary workers to have an expectation of continuity in their work relationship. Among the self-employed, business owners seem likely to expect that their work arrangement will continue. Some independent contractors and freelancers also may have an expectation of continuity, but to the extent that they work on a task basis this is less likely to be the case and we have entered "no" for them in the column capturing this characteristic. Day laborers and on-demand or platform workers are unlikely to anticipate a continuing work relationship.

The third and fourth work characteristic columns pertain to whether the person in the listed work arrangement has a predictable work schedule and whether their earnings when working are predictable. Predictable hours and earnings are part of what defines a traditional employee arrangement. During the term of her employment, a direct hire temporary is likely to have relatively predictable hours and earnings, and the same is likely to be true of most contract company workers. An on-call worker will have unpredictable hours, but her pay while working is likely to be relatively predictable. Among the self-employed, a business owner's schedule may not be entirely predictable, but we would expect there 
to be a fair amount of regularity in her work hours and have entered "yes" in the relevant rows of the column capturing the predictability of hours; the earnings from time devoted to a business, however, may be less predictable. Both hours and earnings are apt to be unpredictable for independent contractors or freelancers, day laborers and on-demand or platform workers.

A final work characteristic identified in the table, applicable only to those who are paid a wage or salary, captures whether on-the-job supervision is provided by the same firm that pays the worker's salary. This would be the case for traditional employees, on-call workers, and direct hire temporary workers, all of whom are hired onto the payroll of the firm requiring their services. It would not be the case, however, for the employees of temporary help agencies or other contract firms who perform tasks under the supervision of the client firm but are paid by a different firm. This characteristic is associated with the so-called fissuring in the labor market that has been identified by some scholars as having weakened the opportunities and protections for workers who previously would have been employed directly by the firm for which they provide services but now are employed by a different company (Weil 2014).

\section{Capturing Different Work Arrangements in Household Survey and Administrative Data}

The next three columns of Table 1 indicate where the different work arrangements might appear in household survey or tax data. Household surveys such as the CPS, the American Community Survey (ACS) and others commonly distinguish among wage and salary workers, the incorporated self-employed and the unincorporated self-employed. In addition to traditional employees, on-call workers, direct hire temporaries, temporary help agency workers, PEO workers and other contract company workers generally should be categorized as wage and salary in these data. The incorporated self-employed also typically are treated as wage and salary workers in published household survey statistics, though if a different breakout is desired, it often is possible to identify them separately. Work arrangements for which the table's first column indicated not being paid a wage or salary generally should be categorized as unincorporated self-employment in the household survey data; this includes partnerships, sole 
proprietorships, most independent contractors and freelancers, day laborers, and on-demand or platform workers.

Turning to tax data, wage and salary earnings produce information returns that are provided to the employee and submitted to the Internal Revenue Service. A Form W-2 is required for any job on which an individual earns $\$ 600$ or more in wages or salary during a year. The same form is used by owners of incorporated businesses to report wages or salaries they pay themselves. Incorporated business owners also may receive distributions of business profits reported on a Schedule K-1 or payments of dividends reported on a Form 1099-DIV. Proceeds flowing from a partnership business to the individual partners are reported on a Schedule K-1. In contrast, sole proprietors and others doing non-employee work may earn income for which there is no associated information return. If there is an information return, it is likely to be a Form 1099-MISC (for payments of non-employee compensation of $\$ 600$ or more by a business to any individual during a year) or, since 2011, possibly a Form 1099-K (for settlement of payment card transactions or of transactions conducted through third-party networks such as PayPal that exceed certain thresholds).

Anyone who receives self-employment income for services provided in excess of $\$ 433$ over the course of a year is required to file a Schedule SE, the form that is used to calculate self-employed individuals’ payroll tax liability. This applies to anyone who receives distributions of partnership income or has other earnings from unincorporated self-employment activity. For the purpose of calculating personal income tax liability, individual tax filers use Schedule E to report receipt of S-corporation profits or partnership income and Schedule C to report income from an unincorporated sole proprietorship or other self-employment activity. The requirement to include a Schedule C with a selfemployed tax filer’s return applies even if the individual received no information returns in connection with their taxable earnings and even if business expenses fully offset the gross payments received.

The final column of Table 1 indicates where we should expect gig employment to appear in household survey and administrative data. We first need to define what we mean by a gig worker. The term "gig" originated in the music industry, where musicians go into the studio to record one song or play 
in a band for one performance. The musicians with such gigs have no expectation of recording at the same studio the following day or playing with the same band the following night. Borrowing from the music industry, we define "gig employment” as one-off jobs on which workers are paid for a particular task or for a defined period of time. In terms of the work arrangement characteristics examined in Table 1, a gig worker is not paid a wage or salary; does not have an implicit or explicit contract for a continuing work relationship; and does not have a predictable work schedule or predictable earnings when working. Applying this definition to the characteristics we have assigned to the various work arrangements, independent contractors and freelancers, day laborers and on-demand or platform workers should be considered gig workers.

In household survey data, gig workers should be included among the unincorporated selfemployed, but that group also includes people who are not gig workers. Because many household surveys focus on main jobs to the exclusion of supplemental work activities, however, household survey data may not capture gig work done in addition to a person's primary employment. In tax data, some gig workers may receive a Form 1099-MISC, but the same form also may be used to report payments to other selfemployed individuals who are not gig workers. The same is true of payments reported on a Form 1099K. We would need to know more about the reason a payment was received - specifically, whether it was a payment to an unincorporated self-employed worker performing a one-off job - to determine whether the recipient should be considered a gig worker. Further, not all gig work generates either a Form 1099MISC or Form 1099-K. All gig workers who are required to file a tax return should report their gross earnings and expenses from their gig work on a Schedule C. In addition, so long as their earnings exceed a minimum threshold, they should report their net earnings from gig work on a Schedule SE. While all gig workers generally should be filing these schedules, not all Schedule C or Schedule SE filers are gig workers.

To the extent that household survey data or tax data allow us to identify everyone with either primary or secondary employment as an unincorporated self-employed worker, in principle that information should provide an upper bound on the number of gig workers. Trends in unincorporated self- 
employment, which can be constructed using publicly available data from multiple sources, thus are a first place to look for suggestive evidence of whether gig employment has been growing over time.

\section{Historical Data on Non-Employee Work Arrangements}

Several household surveys conducted by the U.S. Census Bureau produce regular information about the prevalence of self-employment among working Americans. The monthly CPS, conducted by the Census Bureau for the Bureau of Labor Statistics, is the source of official statistics about the U.S. labor market. It is an interviewer-administered household survey that includes questions about labor market activity during a specific reference week. CPS data can be used to identify household members whose main job during the survey reference week was in self-employment. More limited information is collected about second jobs. Each spring, the Annual Social and Economic (ASEC) supplement to the CPS collects information about income and employment over the prior calendar year, including information on the longest job and on calendar year self-employment earnings. Finally, since 2005, the American Community Survey (ACS), a large mixed-mode survey conducted on a rolling basis throughout the year, has been another source of published self-employment estimates. These refer to the main job during the survey’s reference week (described to the respondent as “last week”).

More recently, analysts have turned to tax records in an effort to learn about the prevalence and nature of non-employee work. Sole proprietors and general partners who have net earnings at or above a fairly low threshold (set since 1994 at \$433) are required to file a Schedule SE, Self-Employment Tax. The Master Earnings File (MEF) database maintained by the Social Security Administration incorporates information on self-employment income from the Schedule SE together with information on any wage earnings reported on a Form W-2 that a person may have received during the year. The Census Bureau receives an extract (called the Detailed Earnings Record, or DER) that includes MEF records for each CPS respondent for whom a Protected Identification Key (PIK), an encrypted Social Security Number, is available. This extract can be used to estimate the number of people filing a Schedule SE each year. In addition, any tax filer with gross nonfarm self-employment income earned as an unincorporated sole 
proprietor (including income earned as an independent contractor or freelancer, day laborer, or ondemand or platform worker) is required to file a Schedule C. Schedule C information is a key ingredient in the construction of the master list of nonemployer businesses maintained by the Census Bureau. ${ }^{4}$

Whereas both Schedule SE and Schedule C are filed by the recipients of self-employment income, Form 1099-MISC is filed by businesses that make payments of non-employee income of $\$ 600$ or more to any entity or individual during the calendar year. Tracking entities or people who received one or more Form 1099-MISC reporting non-employee compensation during a calendar year offers another perspective on trends in self-employment, though the use of these data is complicated by the fact that a Form 1099-MISC with a checked non-employee compensation box may be reporting a payment to a business rather than an individual and a considerable amount of self-employment income has no associated Form 1099-MISC. ${ }^{5}$ Since 2011, Form 1099-K has been used to report settlement of payment card transactions or settlement of third-party network transactions that exceed $\$ 20,000$ or 200 transactions per year. Some self-employed individuals may receive a Form 1099-K, but this is relatively unusual and most Form 1099-Ks are not issued to unincorporated self-employed individuals.

Figure 1 shows the trend in a number of different measures of the self-employment rate (the number self-employed under different definitions as a percent of the corresponding total employment measure). The four series at the bottom of Figure 1 all derive from household survey data. The series based on the monthly CPS captures the percent of employed people who are unincorporated selfemployed on the main job held during the survey reference week, averaged across the twelve months of the year. This series has trended steadily downwards, falling from 8.3\% in 1996 to $6.3 \%$ in 2016 . The main job series based on ACS data is conceptually comparable to the monthly CPS series and, although slightly lower in level, shows a similar downward trend over the years for which it is available. There are

\footnotetext{
${ }^{4}$ Businesses are included on the list if they report $\$ 1,000$ or more in gross revenue (or, in construction, $\$ 1$ or more in gross revenue). In addition to information about unincorporated sole proprietors derived from Schedule $\mathrm{C}$ filings, the master list of nonemployer businesses also incorporates tax return information about C-Corporations, S-Corporations and partnership businesses that do not have employees.

${ }^{5}$ The Data Appendix provides additional details about the various household survey and administrative data sources just described. Although occasional supplements to the monthly CPS have asked more probing questions about the nature of individuals' employment arrangements, these questions have not been asked routinely and consideration of the data generated by these occasional supplements is deferred to later in the paper
} 
two household survey measures derived from the annual CPS-ASEC. The first shows the percent of people with any employment during the year whose longest job was in unincorporated self-employment and who had positive self-employment earnings. The second shows the percent of people with employment during the year who were reported to be unincorporated self-employed on their longest job and to have had positive self-employment earnings or, if the longest job was not unincorporated selfemployment, to have had positive self-employment income from work outside of their longest job. These series have fluctuated somewhat but exhibit no clear trend. By construction, the first three of these series do not capture self-employment that is supplemental to a primary job. In principle, however, the CPSASEC series that makes use of the information on self-employment income during the year should pick up both primary and secondary self-employment activity and that measure behaves similarly to the others.

Five self-employment series based on administrative data series appear in the upper part of Figure 1. These series are most comparable in concept to the CPS-ASEC series based on earnings during the calendar year. The numerator in each case is some measure of the number of people or entities with selfemployment earnings during the year; the denominator for all of the measures is the number of individuals with earnings from any source in the DER. The estimated share of persons with any earnings in the DER who have self-employment earnings has trended upwards, rising from 9.5\% in 1996 to 11.3\% in 2012 (the last year for which we currently have these data). ${ }^{6}$ Census counts of nonemployers are available from 1997 through 2016; sole-proprietor nonemployers are identified separately in published data beginning in 2004. Both have trended upwards as a percent of the number of earners and, over the period from 2004 through 2016 when both are available, the upward trend in the series for soleproprietor nonemployers has tracked the upward trend in the series for nonemployers overall. ${ }^{7}$ Finally, the number of entities receiving non-employee compensation reported on a Form 1099-MISC, taking individuals and businesses together, and the number of individuals for whom such compensation was

\footnotetext{
${ }^{6}$ The DER estimates are based on a data file containing linked individual records from the CPS-ASEC and the DER that is discussed in the next section of the paper.

${ }^{7}$ For 2013, 2014 and 2015, we do not have the DER estimate of the number of people with earnings during the year needed to construct the self-employment rates based on the Census nonemployer data. We have extrapolated the 2012 DER employment estimate forward using information on the change in employment from the Current Employment Statistics survey. See the Data Appendix for further details.
} 
reported are currently available for the period 2000-2012. These measures also have grown relative to the number of people with earnings.

Figure 1 makes clear that different data sources provide quite different answers to the simple question of what is the level and trend of self-employment in the U.S. economy. Others have noted divergences between specific series; Katz and Krueger (2016), for example, show the divergent trends in estimates of self-employment based on monthly CPS data and IRS Schedule C filings. Figure 1 shows that this divergence is quite general. Household surveys consistently show lower levels of selfemployment than tax data and a relatively flat or declining long-term trend in self-employment as contrasted with the upward trend that is evident in tax data.

It would be nice to be able to say that one or the other type of measure - estimates based on household survey data or estimates based on tax data - accurately represents the prevalence and evolution of self-employment over time. In truth, however, measures of both types suffer from potential weaknesses. On the one hand, constraints on the length of the monthly CPS and ACS questionnaires mean that neither survey instrument probes deeply about household members’ work arrangements. This may contribute to a variety of reporting errors. For example, a household survey respondent might fail to mention informal work that they do not think of as a job, something that further probing might uncover. To take another example, a household member who is doing work for a business may be reported as an employee of that business, even in cases where further probing might reveal that the person is in fact an independent contractor or freelancer. To the extent that non-traditional work arrangements are of growing importance, these problems could have become more serious over time.

On the other hand, administrative data capture only the information that is reported to the tax authorities on tax or information returns. Non-reporting or under-reporting of income to the tax authorities is an acknowledged issue, especially with regard to self-employment income and other types of income that do not generate an information return that is submitted to the IRS. As already noted, anyone who makes payments of wage or salary income of $\$ 600$ or more to an employee over the course of the year is required to file a Form W-2 with the IRS to document that payment. Businesses that make 
payments of $\$ 600$ or more to a self-employed individual for services rendered are required to report those payments on a Form 1099-MISC. In 2011, business tax forms were modified so that business owners now must certify when they file their tax returns that all required Form 1099-MISCs have been completed and submitted. Also taking effect in 2011 was a requirement that payment settlement entities that process electronic payments to businesses must report those payments to the IRS on a Form 1099-K if they exceed certain thresholds. There is no requirement, however, for households that pay for services to file a 1099-MISC. Despite efforts by the Congress to tighten the requirements for information reporting, a great deal of self-employment income generates no associated information return (Government Accountability Office 2007, Slemrod et al 2017). Further, information returns capture only gross payments. To determine self-employment earnings, it is equally important to be able to gauge the expenses incurred in connection with this gross income, but these expenses generally are not subject to required information reporting (Government Accountability Office 2007, Slemrod et al 2017). Not surprisingly, tax audit studies have shown that virtually all wage and salary income is reported on individual tax returns, but that a notably smaller share of net non-farm proprietor income and net farm income is reported (Slemrod and Bakija 2008).

One question is whether changes in information reporting requirements, such as those introduced in 2011, could have affected the reported prevalence and amounts of self-employment income. Research to date has not identified discontinuities in the administrative self-employment time series associated with changes in reporting requirements. With respect specifically to the changes introduced in 2011, this may be because the relatively minor increases in reported gross self-employment income that the changes appear to have induced were offset by the reporting of increased expenses (Slemrod et al 2017).

Another potential issue to flag is that, in the household survey data we have examined, our attention has been focused on the unincorporated self-employed, the group that is conceptually most comparable to the self-employment for which we have information in the DER. If the self-employed have become more likely over time to incorporate, the trend in a series that included the incorporated selfemployed might be more meaningful (Hipple and Hammond 2016). We have recomputed both the 
monthly CPS and the ACS self-employment series with the incorporated self-employed included.

Including them in the series does not change the conclusion that self-employment as measured in the household survey data has been steady or declining, rather than increasing as in the tax-based administrative data.

\section{Reconciling Household Survey and Administrative Estimates of Non-employee Work}

The most straightforward approach to understanding the discrepancies between household survey and administrative data estimates of self-employment is to compare information from the two sources for the same set of people. Using an internal Census Bureau identifier — the Protected Identification Key or PIK—-we have linked records from the Annual Social and Economic Supplement to the CPS (the CPSASEC) to administrative records from the DER for the years 1996 through 2012 (the latest year for which we currently have data from the DER). The PIK is missing for approximately 20 to $30 \%$ of CPSASEC records, depending on the year. As described in the Data Appendix, we have reweighted the records with a PIK based on their characteristics to represent the population age 16 and older as a whole. In both of the data sets incorporated into the linked file, we identify unincorporated self-employment based on reports of self-employment earnings during the calendar year. To be more specific, in the CPSASEC, a person is defined as self-employed if they have a longest job during the year that is unincorporated self-employed and positive self-employment earnings or, if the longest job was not unincorporated self-employed, if they have positive self-employment income from some other job. ${ }^{8}$ In the DER, a person is defined as self-employed if they had self-employment earnings reported on a Schedule SE.

We have used these data to ask how well the CPS-ASEC and the DER agree with respect to the classification of individuals as self-employed. Table 2 displays a weighted cross-tabulation of selfemployment status in the CPS-ASEC with self-employment status in the DER, using data that are pooled

\footnotetext{
${ }^{8}$ In the CPS-ASEC, we do not know whether self-employment earnings other than from the longest job are from incorporated or unincorporated self-employment, though we expect most self-employment outside of the longest job to be unincorporated self-employment. See the Data Appendix for some evidence related to this point. 
across the years 1996-2012. Although the two data sources should be measuring essentially the same thing, there is substantial disagreement between them regarding individuals' self-employment status. On average over the 17 years for which we have data, $65.4 \%$ of those with self-employment income in the DER do not report any self-employment income in the CPS. Conversely, 51.1\% of those with selfemployment income in the CPS-ASEC do not report any self-employment income in the DER.

The fact that there is disagreement between the household survey and administrative data employment measures is not surprising. In earlier research, we found that, on average over the period 1996-2003, about $6 \%$ of individuals who had unemployment insurance (UI) earnings during the first quarter of the year reported no CPS wage-and-salary employment in a UI-covered sector during the year's first three months; conversely, about $18 \%$ of individuals reporting CPS wage-and-salary employment in a UI-covered sector during the first three months of the year had no first-quarter UI earnings (Abraham et al 2013). Similarly, in weighted tabulations using the linked data file that we are using to explore the sources of discrepancy in alternative self-employment series, 9.3\% of those with DER wage-and- salary income had no reported CPS-ASEC wage-and-salary income for the same year; conversely, $12.4 \%$ of those with reported CPS-ASEC wage-and-salary income for a year had no DER wage-and-salary income for that same year.

What is surprising, however, is the size of the off-diagonal cells in the tabulations shown in Table 2. Whether taking the DER self-employed or the CPS self-employed as the base, a majority of those who are categorized as self-employed in the data set in question are not categorized as such in the other data set. At least to some extent, this reflects the complexity of self-employment activity. There are many different types of self-employment work and a highly heterogeneous set of arrangements under which such work might occur. Neither the household survey data nor the administrative data may be ideally suited to pick up all of that activity. ${ }^{9}$

\footnotetext{
${ }^{9}$ Some of the information used to categorize individuals as self-employed in the CPS-ASEC is imputed rather than directly reported. We chose to retain CPS-ASEC records with imputed information because that makes the data we analyze more consistent with the data used in the production of published statistics. Usable information on which values are imputed is available from 1997 forward. In calculations for the 1997-2012 period based on a sample restricted to cases with directly reported information, we estimate that $63.4 \%$ of those with DER self-employment have no CPS-
} 
We also are interested in how the discrepancy between the CPS-ASEC and the DER measures of self-employment has changed over time. Figure 2A displays the number of self-employed people as measured in the CPS-ASEC annual earnings data and the corresponding measure based on earnings data from the DER. While self-employment based on the DER grew markedly between 1996 and the mid2000s, the corresponding CPS-ASEC measure was lower to start with and has been stagnant. Figure 2B shows the off-diagonals associated with cross-tabulating the CPS-ASEC and DER data on a year-byyear basis. That is, it plots the number of people who are self-employed in the DER but not the CPSASEC and, separately, the number who are self-employed in the CPS-ASEC but not the DER. It is apparent that virtually all of the growth in DER self-employment relative to CPS-ASEC selfemployment can be attributed to growth in the number of people who are self-employed in the DER but not in the CPS-ASEC.

To further explore the discrepancy between the two measures of self-employment, we have looked a bit more closely at these off-diagonals, grouping those who are self-employed in the DER but not the CPS-ASEC into three mutually exclusive categories:

1) No CPS employment: No wage-and-salary or self-employment income in the CPS-ASEC; selfemployment income in the DER. ${ }^{10}$

2) Self-employment second job not reported in CPS: Only wage-and-salary income in the CPSASEC; both wage-and-salary income and self-employment income in the DER.

3) CPS job wage and salary, classification issue: Only wage-and-salary income in the CPS-ASEC; only self-employment income in the DER.

Those in the first two groups may be people performing self-employment work who do not think to report it (or for whom the CPS respondent in their household does not think to report it), whether because the activity in question generated only a small amount of earnings or for some other reason. The third group may be capturing those who think of themselves as employees and may in fact be employees 
according to the relevant legal criteria, but are paid as non-employees and classified that way in the tax data. Given the growing concerns about worker misclassification (see, e.g., Leberstein 2012), for some purposes this group may be the most interesting.

We also have grouped those who are self-employed in the CPS-ASEC but not in the DER into three mutually exclusive categories:

4) No DER employment: No wage-and-salary or self-employment income in the DER; selfemployment income in the CPS-ASEC. ${ }^{11}$

5) Self-employment second job not recorded in the DER: Only wage-and-salary income in the DER; both wage-and-salary income and self-employment income in the CPS-ASEC.

6) CPS job self-employed, classification issue: Only wage-and-salary income in the DER; only selfemployment income in the CPS-ASEC.

The fourth and fifth categories capture self-employment income that is reported in the CPS but does not appear in the tax data, either work generating too little income to trigger tax reporting requirements or off-the-books work. Category six may be capturing individuals who are indeed self- employed but operate an incorporated business, meaning that they should not have been counted in the CPS measure of unincorporated self-employment and would appear in the tax data as having wage and salary income, but not self-employment income.

Figure 3A shows the evolution of the three groups within the DER $\{\mathrm{SE}=1\} / \mathrm{CPS}-\mathrm{ASEC}\{\mathrm{SE}=0\}$ category; Figure 3B shows the evolution of the three groups within the CPS-ASEC $\{\mathrm{SE}=1\} / \mathrm{DER}\{\mathrm{SE}=0\}$ category. Whereas there has been growth in all three of the DER $\{\mathrm{SE}=1\} / \mathrm{CPS}-\mathrm{ASEC}\{\mathrm{SE}=0\}$ groups, employment in the three CPS-ASEC $\{\mathrm{SE}=1\} / \mathrm{DER}\{\mathrm{SE}=0\}$ groups has changed very little.

One way to summarize the information presented in these figures is to ask what share of the growing discrepancy between the number of people with self-employment income according to the DER and the number of self-employed people according to the CPS-ASEC is accounted for by each of the

\footnotetext{
${ }^{11}$ Individuals in this category may have only self-employment income or both wage-and-salary and self-employment income in the CPS-ASEC. 
groups. For this purpose, we have averaged the numbers for the two starting years and the two ending years in our data series, then calculated the overall change in the discrepancy between those averaged endpoints. Note that either increases in the size of the DER $\{\mathrm{SE}=1\} / \mathrm{CPS}-\mathrm{ASEC}\{\mathrm{SE}=0\}$ groups or decreases in the size of the CPS-ASEC $\{\mathrm{SE}=1\} / \mathrm{DER}\{\mathrm{SE}=0\}$ groups could have added to the overall discrepancy.

The percentages of the growth in the overall discrepancy accounted for by each of the six groups described above are shown in Table 3. As was apparent from Figure 2, the growing discrepancy between the DER and CPS-ASEC estimates of self-employment is accounted for entirely by the growing number of people identified as self-employed in the DER who are not so identified in the CPS-ASEC. This growth is split roughly evenly between the three $\mathrm{DER}\{\mathrm{SE}=1\} / \mathrm{CPS}-\mathrm{ASEC}\{\mathrm{SE}=0\}$ groups. The net effect of changes in the size of the CPS-ASEC $\{\mathrm{SE}=1\} / \mathrm{DER}\{\mathrm{SE}=0\}$ off-diagonals is small and works in the direction of slightly offsetting the growing size of the DER $\{\mathrm{SE}=1\} / \mathrm{CPS}-\mathrm{ASEC}\{\mathrm{SE}=0\}$ off-diagonals. In other words, the main issue appears to be that there are an increasing number of people who are earning self-employment income and reporting that income to the tax authorities, but for whom that income is not being reported in the CPS-ASEC. ${ }^{12}$

A possible explanation for the increasing number of people with self-employment activity that is captured in the DER but not reported in the CPS-ASEC might be that more of them are doing selfemployment work that generates only a small amount of income. We note, however, that the average selfemployment earnings of those with self-employment captured in the DER but not the CPS-ASEC are relatively substantial, averaging roughly \$13,700 in 2009 dollars over the years 1996 through 2012 covered by our sample, and, further, that this average earnings level has not trended downwards over time. ${ }^{13}$

\footnotetext{
${ }^{12}$ In the reweighted sample that excludes cases with imputed information, which can be constructed for the period from 1997 through 2012, it is also the case that each of the three groups with DER self-employment but no CPS-ASEC selfemployment accounts for roughly a third of the discrepancy in growth between the DER and CPS-ASEC series.

${ }^{13}$ Among those who have self-employment earnings in the DER but not in the CPS-ASEC, DER earnings are largest for those with only wage and salary earnings in the CPS-ASEC and only self-employment earnings in the DER, averaging just over \$23,000 in 2009 dollars over the years for which we have data. DER self-employment earnings averaged about $\$ 10,900$ for the group with no CPS-ASEC employment and about $\$ 7,500$ for those who are missing a self-employment
} 


\section{Improving Household Survey Measures of Non-Employee Work}

The preceding discussion has documented that the CPS-ASEC information on calendar year earnings is missing a significant and increasing amount of self-employment activity. Because this series has behaved so similarly to other series based on household survey data, there is reason to suspect that the same is true of other household survey measures of self-employment.

One way to improve existing household survey measures of self-employment and alternative work arrangements more generally would be to add survey questions that probe more directly regarding these arrangements, either as part of the core survey or (perhaps more plausibly) on periodic supplements. The Contingent Worker Supplement (CWS) to the CPS, fielded on several occasions between 1995 and 2017, has included questions both about whether the individual has an explicit or implicit contract for continued employment and about alternative work arrangements—whether the person's main job was as an independent contractor, on-call worker, temporary agency worker or worker at a contract firm (see Cohany 1996, Polivka 1996a, Polivka 1996b). The smaller Quality of Worklife (QWL) supplement to the General Social Survey also has produced estimates on the prevalence of the same four alternative work arrangements on the main job.

Estimates of the prevalence of alternative work arrangements based on the CWS for six years between 1995 and 2017 are shown in the top panel of Table 4; estimates from the QWL supplement to the GSS for four years between 2002 and 2014 are shown in the table’s bottom panel. Although the estimates from the two surveys differ with regard to the estimated prevalence of some types of work, in particular work as an independent contractor, they agree that the prevalence of the different alternative work arrangements has not trended upwards over time. It is important to note, however, that these questions were asked only about people who had already been identified as employed in response to the survey’s standard employment questions and only about their main jobs. Both of these features of the two surveys

second job in the CPS-ASEC. There was no downward trend in DER self-employment earnings over our sample period for any of the three groups. 
mean that there is likely to be work under alternative arrangements that, in part by design, they do not capture.

In October and November 2015, before the fielding of the 2017 CWS, Lawrence Katz and Alan Krueger arranged for the core CWS questions to be collected on the Rand-Princeton Contingent Work Survey (RPCWS) administered as part of the Rand Corporation's online American Life Panel (ALP) (Katz and Krueger 2016). The intention was that the RPCWS would produce estimates for 2015 that could be compared to the CWS estimates for earlier years. In contrast to the 2017 CWS, the 2015 RPCWS produced substantially higher prevalence rates for all four types of alternative work than had been estimated in the 2005 CWS, results that were interpreted as evidence of substantial growth in the prevalence of these arrangements on individuals’ main jobs. Given these findings, many people were surprised when the 2017 CWS estimates turned out to be so similar to the 2005 CWS estimates. There are several reasons, however, to have suspected that the RPCWS estimates might not be directly comparable to the earlier CWS estimates.

First, the RPCWS data were collected through an online panel, the ALP, whose members are assembled from a variety of sources with an unknown response rate. ${ }^{14}$ Given the way in which it was assembled, the RPCWS sample may be less representative of the population than the CWS sample in ways that reweighting based on observables cannot fully correct. Second, whereas the CWS asks respondents to provide information for all members of their households, the RPCWS asks respondents to report only for themselves. To the extent that respondents are able to report more fully about their own experiences than about the experiences of others in their household, this could mean that relying only on self-reports will produce more accurate information than accepting both self and proxy reports, but by the same token may undermine the comparability of the RPCWS to the CWS. Third, the RPCWS and the CWS collected information for different times of the year, with the CWS asking about work during a mid-February reference week and the RPCWS about work during an October or November reference week. It is possible that the reliance on alternative work arrangements fell between 2015 and 2017 as the

${ }^{14}$ See Pollard and Baird (2017) for a description of the methods used to create the ALP panel. 
labor market tightened, but this seems unlikely to explain the large difference in the estimates from the 2015 RPCWS and the 2017 CWS. We view the different findings obtained in the two surveys as a cautionary tale about the importance of consistency in measurement for assessing trends in work arrangements.

Beyond the issue of comparing the RPCWS to the CWS, there is the concern already noted that the CWS, GSS and RPCWS all could be missing non-employee work on the part of people who are not categorized as employed based on the standard employment questions or whose self-employment is not their main job. In the linked data described in the previous section of the paper, there are a significant number of people for whom no self-employment during the year is recorded in the household data but who have self-employment income that is captured in the DER. These are divided among people with no income from employment at all in the CPS (19.3\% on average over the 1996 to 2012 period); people with only wage and salary income in the CPS but wage and salary income plus self-employment income in the DER (44.9\% on average); and people who have only wage and salary income in the CPS and only selfemployment income in the DER (35.7\% on average).${ }^{15}$ While these numbers refer to self-employment at any point during the year rather than to self-employment at a point in time, they suggest that there may be a significant amount of non-employee work that would not be uncovered by probing only about an already-reported main job (the final group in the cited numbers based on the linked annual data) and that such a focus may miss important ongoing changes.

Several other recent surveys have contained questions designed specifically to learn about the prevalence of informal work activity. The Enterprising and Informal Work Activities (EIWA) Survey (Robles and McGee 2016), administered as an online survey to the GfK KnowledgePanel in October and November of 2015, contained a battery of items asking respondents about informal income-generating activities over the prior six months, including in-person service activities such as child care, housecleaning or landscaping; selling new or used items at garage sales or flea markets; and selling services, selling items or renting property online. The EIWA estimates indicate that $36 \%$ of the adult U.S.

${ }^{15}$ In the previously-mentioned data set that drops imputed observations, the corresponding percentages for the period $1997-2012$ are $19.5 \%, 45.0 \%$ and $35.5 \%$. 
population engaged in at least one of these activities during the six-month reference period. Although there might be debate about whether renting or selling items should count as work activity, the survey estimates show that $27 \%$ of the adult population earned income by housecleaning, house sitting, yard work or other property maintenance tasks and that $17 \%$ earned income by babysitting or providing childcare services.

The 2015 Survey of Household Economics and Decisionmaking (SHED), also administered via the GfK KnowledgePanel, contained a single question about whether a respondent was currently engaged in informal work activity. Among adults who were not students and not retired, about $20 \%$ of those under age $30,15 \%$ of those age 30 to 44 , and $11 \%$ of those age 45 and older said they were engaged in informal work (Board of Governors 2016). The 2016 SHED adopted the more detailed set of questions about informal work activity developed for the EIWA and a one-month reference period. An estimated $28 \%$ of all adults reported having earned money from informal work activities during the previous month (Board of Governors 2017). A final recent survey, the Survey of Informal Work Participation (SIWP), also finds high rates of participation in informal work activities. Among non-retired adults age 21 and older surveyed in the two waves of the survey conducted in 2015, an estimated $37 \%$ were currently engaged in paid informal work, not including survey work, and 20\% were engaged in informal work after excluding work related to renting and selling (Bracha and Burke 2016). ${ }^{16}$

A recent survey experiment described in Abraham and Amaya (2018) provides some additional evidence about how different approaches to probing for informal employment might affect the share of people for whom employment activity is reported (the employment rate) and the share of those with employment for whom more than one job is reported (the multiple job holding rate). The experiment was

\footnotetext{
${ }^{16}$ In addition to these surveys, the Survey of Income and Program Participation includes a category for reported work on a person's main job that cannot easily be classified as either work for an employee or self-employment. The utility of these data is limited by the fact that they do not allow different arrangements within the "other" category to be distinguished. The McKinsey Global Institute (MGI) independent work survey (Manyika et al 2016) also attempted to capture all informal or independent work, whether it represented a person's primary work or was supplemental to a primary job. The independent work concept applied in the MGI survey, however, is not comparable to that applied in other research.
} 
embedded in a survey carried out for the 2016 Joint Program in Survey Methodology (JPSM) practicum.

Subjects for the survey were recruited using Mechanical Turk, Amazon’s crowdsourcing platform.

The survey collected information on the characteristics of the members of respondents'

households. It also asked questions to identify each household member’s employment status and, for those who were employed, whether they held more than one job. With the exception of some special questions concerning sexual orientation and gender identify included for testing, all of the questions about household members' characteristics and employment status were taken directly from the CPS questionnaire. Additional questions about informal work activity were asked about one randomlyselected member of each survey respondent's household. In one version, randomly assigned to half of the cases, respondents were asked a global yes/no question about whether there had been any such work activity during the reference week (the global question). In the second version, respondents were asked about each of six different possible types of informal work activity, with examples provided for each of them, and to indicate whether any other type of informal work activity had been performed (the detailed question). ${ }^{17}$ In cases where employment had already been reported for the person to whom the added probe applied, the respondent was asked to indicate whether any reported informal work activity had been included in the responses to the standard CPS employment questions. Employment rates and multiple job holding rates were computed based on the responses to the CPS questions and then were re-computed to incorporate the additional work activity uncovered by probing.

The first row in the upper panel of Table 5, summarizing selected results from Abraham and Amaya (2018), displays the employment rate that is estimated based on the standard CPS questions; the second row displays the augmented employment rate that incorporates the additional information provided in response to the informal employment probe; and the third row shows the difference between the two estimates. The employment rate is defined as the percent of the sample categorized as having been employed during the survey reference week. The second panel of the table reports similar

\footnotetext{
${ }^{17}$ The six types of activity in addition to the "other" category were services to other people; services to a self-employed individual or business; performing as an actor, musician or entertainer; driving for a ride-sharing service; assisting with medical, marketing or other research; or posting videos, blogs or other content online. A list of examples was given for each category.
} 
information on the multiple job-holding rate for those categorized as employed based on the standard CPS questions. The multiple job holding rate is the percent of this group who had more than one job during the survey reference week. Estimates are shown separately for respondents asked to report for themselves and those asked to report for another member of their household, in each case differentiated by whether the respondent received the global probe or the more detailed probe.

Probing to ask about informal work activity produced notably higher estimated employment and multiple job-holding rates whether respondents were reporting for themselves and or for another member of their household, and whether the respondent received the global or the detailed probe. Although the sample of Mechanical Turkers used in the study is not representative of the population as a whole and the magnitude of the changes in these estimated rates likely would have been different in a more representative sample, the fact that probing has such a consistent effect on the estimates suggests that learning about informal work activity is likely to require asking more than the standard employment questions.

In addition, the estimates suggest that asking the global question versus the more detailed question about informal work may make a larger difference when the respondent is answering questions about someone else. For those reporting about their own work activity, the two forms of the question have very comparable impacts, and the differences between the effects of the two question treatments are not statistically significant. In contrast, when the respondent is reporting for another household member, asking the detailed probe rather than the global probe produces a larger increase in both the estimated employment rate and the estimated multiple job-holding rate. Given the nature of the survey sample, the magnitudes of the differences between the estimates for respondents and those for others in their household are unlikely to generalize, but as discussed more fully in Abraham and Amaya (2018), it is informative that detailed probing makes a larger difference compared to using a global probe when respondents are being asked about others in the household rather than about themselves.

Other recent research also has produced results suggesting that the standard CPS questions may not fully capture informal work activity. The SIWP surveys fielded in 2015 included employment 
questions similar to those on the CPS together with additional questions about informal work. Assuming that anyone who was currently engaged in informal work activity should have been counted as employed, accounting for that work would have raised the point estimate of the overall employment rate from $62.0 \%$ to $64.6 \%$, though the survey sample was relatively small and this increase was not statistically significant (Bracha and Burke 2016). Preliminary results from a 2015 survey of Mechanical Turk respondents conducted by Lawrence Katz and Alan Krueger indicate that $72 \%$ of small jobs or gigs beyond the main job were not reported in response to the CPS multiple job holding question (Katz 2018). Taken as a whole, these findings suggest that standard household survey questions may miss some individuals’ primary work activities, perhaps because the survey respondent does not think of them as a job, and that there is a sizable risk they will fail to uncover secondary work activity. Devising an appropriate set of more probing questions that could be asked at regular intervals on ongoing household surveys would allow trends in work activity and work arrangements to be gauged more accurately.

\section{Other Sources of Information on Non-employee Work}

In addition to household survey data and the earnings information derived from Schedule SE that we have already discussed, useful information about non-employee work could be gleaned from employer surveys, other tax records and associated data repositories, and information held by private firms. We discuss each of these potential data sources briefly in turn. A central theme of our discussion will be that the integration of survey, administrative and private data has the potential to add important new insights to our understanding of the changing nature of work.

Employer Surveys. A natural approach to learning about alternative work arrangements would be to ask employers. Employer-provided information is unlikely to be especially helpful for learning about how alternative work arrangements fit into workers' careers, but could be quite helpful for learning about the scale of such activity and thus for productivity measurement. Capturing firms' use of contract workers is an issue that has been of particular concern to the federal statistical agencies. More specifically, the agencies have recognized that, for the purpose of allocating economic inputs by sector and measuring 
sectoral productivity, the employees of Professional Employer Organization (PEO) and Temporary Help Service (THS) firms should be assigned to the industry in which they are actually working rather than to staffing services. Dey, Houseman and Polivka (2012) used data from the Occupational Employment Survey on the occupational distribution of staffing services employees together with information from the Contingent Worker Supplement on the industries in which staffing firms place workers to generate estimates of the industry distribution of placements by PEO and THS firms. Over the 1989 to 2004 period studied in their paper, accounting for such placements had a noteworthy impact not only on trends in the input of labor to manufacturing but also on measures of manufacturing labor productivity.

While recognizing that this issue needs to be addressed, both BLS and Census have faced challenges in fully capturing and allocating THS and PEO activity. For a number of cycles, the Economic Census has included questions for PEO firms about the industries in which leased workers are placed (Lombardi and Ono 2010), but similar questions are not asked of temporary help service firms nor is it clear that they would be able to answer them. At BLS, a study was carried out in 2005 to assess the feasibility of collecting information from THS and PEO firms in the Current Employment Statistics (CES) survey on where they placed workers. The conclusion was that many THS and PEO firms do not have records concerning the industry of their clients and that a substantial minority would be unable or unwilling to provide this information on the CES (Bureau of Labor Statistics 2005). Both the Census and the BLS efforts just described sought to be able to allocate the employees of the PEO and THS firms across industries, an important but limited objective. Obtaining this information would still leave unanswered important questions about firms' use of the services of self-employed individuals working on their own account.

In principle, both the services provided by contract company workers and the services provided by sole proprietors, independent contractors, and so on should be captured in the Business Expenses Survey (BES) conducted by the Census Bureau as a part of the Economic Census and its program of annual economic surveys. Rather than asking service suppliers to provide information about their customers, the BES asks the firms who are customers to report on their spending for these services. The information 
obtained through the BES is an important ingredient in the construction of the Input-Output tables. The categories of expenses for which firms are asked to report vary somewhat depending on the industry, but include a category for temporary staff and leased employees obtained through temporary help service or PEO firms, a category for purchased professional and technical services and categories for other types of purchased services. The data are collected annually for manufacturing and services, but only once every five years for other industries, and they are denominated in dollars rather than in the amount of labor used to produce the service in question. Perhaps more important for our purposes, the payments in any category that a firm makes to individuals working as independent contractors or freelancers are aggregated with the payments made to more traditional businesses and cannot be separately identified. Another interesting effort to collect information from the users of labor supplied under various arrangements was the addition of a module on this topic to the 2015 Annual Survey of Entrepreneurs (ASE) ${ }^{18}$ The module included questions on whether the firm used different types of workers—full time; part time; day laborer; temporary help service employee; leased employee; or contractors, subcontractors, independent contractors, or outside consultants—as well as questions regarding what share of the total number of workers were of each type and the types of tasks each type of worker performed. Published data based on the survey module break the estimates out by the age of the business enterprise and other business characteristics. The approach developed for the 2015 ASE is interesting in part because it offers the possibility of insights into the use of non-employee workers by young businesses that may be more innovative in their workforce organizational structure.

Because the Census Bureau does not believe that it has a valid basis for reweighting information collected in response to the type of worker questions to account for either unit or item nonresponse, the published estimates apply only to responding firms, which represent approximately $65 \%$ of all firms, $49 \%$ of employment, $48 \%$ of payroll and $48 \%$ of revenue. Among the firms represented by the responses, 2.9\% used day laborers, 4.6\% used temporary help service employees, $0.8 \%$ used leased employees and $29.7 \%$ used contractors, subcontractors, independent contractors, or outside consultants.

\footnotetext{
${ }^{18}$ The ASE is a survey of approximately 290,000 employer firms, of which just under half are less than 10 years old. See Foster and Norman (2016) for further details about the ASE 
At firms where they were used, workers of these types accounted for fewer than $25 \%$ of all workers at a majority of firms (and for day laborers and temporary help service employees, at a very large majority of firms), but leased employees and contract workers accounted for $75 \%$ or more of workers at between a fifth and a quarter of firms where they were used. There is more to be learned from a careful examination of these new data and this approach to learning about the use of workers under alternative arrangements perhaps could be adapted for use in other settings.

Tax Data. The analysis described earlier in the paper based on CPS data integrated with records from the DER demonstrates the value that can be added by integrating survey and administrative data. Integration of the Form 1099-MISC data into this infrastructure also would be very valuable. Being able to track the longitudinal relationship between individuals identified through their PIKs (SSNs) and the firms identified through their EINs who are issuing the Form 1099-MISC’s to them would be especially interesting. Some individuals may have longstanding self-employment relationships with a single firm; these would be reflected in the individual receiving a 1099-MISC from only one EIN for many years consecutively. Other individuals may be receiving multiple 1099-MISC forms from multiple EINs with considerable turnover in the latter. These two patterns would imply quite different work arrangements from the perspective of both the individual and the firm.

Integration of other sorts of tax data also has the potential to yield new insights. As an example, in other recent work, we have created a data file containing information on self-employed sole proprietors derived from the microdata that underlie the Census Bureau nonemployer statistics, the unemployment insurance wage records contained in the Longitudinal Employer Household Dynamics (LEHD) infrastructure, and personal characteristics from the Census Bureau's Individual Characteristics File. We are using these data to study changes in the Taxi and Limousine Services industry during the period of explosive growth it has experienced following the introduction of online apps for matching workers to customers, looking both at new entrants and incumbents in the industry (Abraham et al 2018). This is just one example of the sorts of analyses that can be carried out using this data infrastructure. 
Financial Data. Anonymized individual-level financial records are another potential source of information about certain forms of non-employee work. In an interesting stream of research, Farrell and Greig (2016a, 2016b) use transaction-level data from customers with JP Morgan Chase banking and credit card accounts to examine flows of income that originate from a set of online platforms identified by the research team. Their findings suggest that online platform workers reflect a small but rapidly growing sector of the workforce. Their findings also suggest, however, that such work is a secondary source of income for most households, reinforcing the importance of looking beyond the main job to develop a complete understanding of the role of non-employee work.

Taking a somewhat different approach, Koustas (2018) analyzes transactions-level data for the users of one company's online personal financial management software. In a sample of individuals identified as receiving regular bi-weekly paychecks, he finds that work as an Uber driver mitigates fluctuations in pay and makes a significant contribution to allowing drivers to smooth their consumption when earnings from a main job fluctuate.

Private Sector Company Data. A final source of information that has been used by researchers interested specifically in the rise of the online platform economy has been person-level data from companies in the online platform sector. Hall and Krueger (2018), for example, have analyzed administrative data on Uber’s “driver/partners” derived from the company’s records. In addition, to enhance the administrative data, they also carried out a survey of these driver/partners. To help provide perspective on their findings, they compare patterns of activity of drivers/partners to information from the American Community Survey on taxi drivers and chauffeurs. They find, for example, that Uber drivers/partners work fewer hours per week than taxi drivers and chauffeurs.

While the findings from these various studies are fascinating, the properties of many of the new private data sources are not yet fully understood. The JP Morgan Chase Institute has taken significant steps to facilitate access by outside researchers to their data and there are other organizations that have developed collaborative relationships with outside researchers. The involvement of outside researchers undoubtedly will be helpful for learning about the strengths and weaknesses of these new types of data. 
Greater access by the research community to such data more generally and, ultimately, integration of these data in an appropriately secure environment with the survey and administrative records discussed above seem like worthy longer-term goals.

\section{Conclusion and a Path Forward}

The widely perceived rise of the gig economy is as yet not well measured or well understood. Gig economy workers should be classified as self-employed, but data from the core traditional household surveys do not show an increase in self-employment activity. There is more evidence in the administrative data of growth in the number of individuals receiving income from self-employment, though much of the growth observed in these data occurred between the mid-1990s and the mid-2000s, prior to the emergence of the app-based gig activity that has captured the popular imagination. If available data on selfemployment are failing to capture ongoing growth in non-employee work activity, estimates of growth in labor inputs may be too low, estimates of aggregate productivity growth may be too high, and the pattern of estimated productivity growth may have been distorted.

A challenge in understanding and measuring the rise of the gig economy is being able to document where such activity fits into the full range of non-employee work. Identifying the key attributes that characterize different forms of non-employee work may help us close in on the traits of jobs that are most appropriately characterized as gig work. In the framework we have developed, gig workers are a subset of the unincorporated self-employed as identified in multiple data sources. We have discussed the challenges to quantifying the prevalence of gig employment using either existing household survey data or administrative records on their own.

Our analysis highlights the potential payoff from improvements in economic measurement along two key dimensions. First, there is a high potential payoff to modules conducted at regular intervals on ongoing household surveys that would probe more deeply about non-employee work activities. This should not be surprising, since gig employment is often a secondary activity that existing household surveys are not well designed to capture. Such activity may not be mentioned by respondents in cases 
where gig work is not a person's primary activity and where the standard household survey employment questions do not cue adequately that it should be reported. To the extent that job attributes define the various types of non-employee work arrangements, probes about employment usefully could be supplemented with questions about job attributes.

A second improvement in economic measurement would be to develop estimates based on survey and administrative data that have been integrated at the individual level. Such integration offers great potential for understanding the changing nature of work, particularly for non-traditional work activities that are inherently difficult to define and measure. Measures derived from tax data show an increasing amount of self-employment that is being missed in household surveys, yet the tax data by themselves are not informative about who these workers are and may be missing “off-the-books” work. Linking tax data with household survey data gives us not only the worker's demographic characteristics, but also the worker's family characteristics - something that is crucially important for understanding how gig employment is related to family income and health insurance coverage. In addition, to the extent that household surveys capture "off-the-books" work that is not reported to the tax authorities, the two sources together may provide a more complete picture than either source alone.

A key missing piece of the puzzle is to understand where non-employee work fits into the career paths of workers. The limited evidence that is currently available suggests that much of the online platform/on-demand non-employee work to date has been supplemental in nature rather than something that participants have undertaken as a primary activity. There is, however, much more to be done to better understand how individuals are combining traditional employment and non-employee work. Longitudinal matched employer-employee data that also fully integrate non-employee work activity will be invaluable for addressing these questions. Developing this data infrastructure will be challenging but is something we believe can be accomplished by building on the work we already have done to integrate the CPSASEC, DER, LEHD and nonemployer business data infrastructures. Being able to add Form 1099-MISC data, including identifiers for both the recipients and the providers of reported payments of non-employee compensation, would greatly enhance the value of the integrated data infrastructure. More generally, we 
envision making use of survey and administrative data to measure and analyze the full taxonomy of nonemployee work in the context of the career paths of workers over their life cycle. 


\section{References}

Abraham, Katharine G. 1988. "Flexible Staffing Arrangements and Employers' Short-term Adjustment Strategies,” in R.A. Hart, ed., Employment, Unemployment and Labour Utilization, London: Unwin Hyman, 288-311.

Abraham, Katharine G. 1990. "Restructuring the Employment Relationship: The Growth of MarketMediated Work Arrangements,” in K.G. Abraham and R.B. McKersie, eds., New Developments in the Labor Market: Toward a New Institutional Paradigm, Cambridge, Massachusetts: MIT Press, 85-119.

Abraham, Katharine G. and Ashley Amaya. 2018. “Probing for Informal Work Activity,” National Bureau of Economic Research Working Paper 24880. August.

Abraham, Katharine G., John Haltiwanger, Kristin Sandusky and James R. Spletzer. 2013. "Exploring Differences in Employment between Household and Establishment Data," Journal of Labor Economics, 31(2) S129-S172.

Abraham, Katharine G., John Haltiwanger, Kristin Sandusky and James R. Spletzer. 2018. "Driving the Gig Economy,” unpublished working paper.

Abraham, Katharine G. and Susan K. Taylor. 1996. "Firms’ Use of Outside Contractors: Theory and Evidence,” Journal of Labor Economics, 14(3) 394-424.

Barker, Kathleen and Kathleen Christensen. 1998. Contingent Work: American Employment Relations in Transition, Ithaca, New York: Cornell University Press.

Board of Governors of the Federal Reserve System. 2016. Report on the Economic Well-Being of U.S. Households in 2015. Washington, D.C.: Board of Governors of the Federal Reserve System.

Board of Governors of the Federal Reserve System. 2017. Report on the Economic Well-Being of U.S. Households in 2016. Washington, D.C.: Board of Governors of the Federal Reserve System.

Bracha, Anat, and Mary A. Burke. 2016. "Who Counts as Employed? Informal Work, Employment Status, and Labor Market Slack.” Federal Reserve Bank of Boston Working Paper 16-29.

Bureau of Economic Analysis. 2017. Concepts and Methods of the U.S. National Income and Product Accounts. Washington, DC.

Bureau of Labor Statistics. 2005. "CES Supplemental Survey Temporary Help and Professional Employer Organization Industries Cognitive Testing Results,” unpublished report. March.

Cohany, Sharon R. 1996. "Workers in alternative employment arrangements,” Monthly Labor Review, October, 31-45.

Dey, Matthew, Susan Houseman, and Anne Polivka. 2012. "Manufacturers' Outsourcing to Staffing Services,” Industrial and Labor Relations Review, 65(3) 533-559.

Dube, Arindrajit and Ethan Kaplan. 2010. "Does Outsourcing Reduce Wages in the Low-Wage Service Occupations? Evidence from Janitors and Guards,” Industrial and Labor Relations Review, 63(2) 287-306. 
Farrell, Diana and Fiona Greig. 2016a. Paychecks, Paydays, and the Online Platform Economy, J.P. Morgan Chase Institute Report. February.

Farrell, Diana and Fiona Greig. 2016b. The Online Platform Economy: Has Growth Peaked?, J.P. Morgan Chase Institute Report. November.

Foster, Lucia, John C. Haltiwanger and C.J. Krizan. 2001. “Aggregate Productivity Growth: Lessons from Microeconomic Evidence,” in C. R. Hulten, E. R. Dean and M. J. Harper, eds., New Developments in Productivity Analysis, Chicago: University of Chicago Press, 303 - 372.

Foster, Lucia and Patrice Norman. 2016. “The Annual Survey of Entrepreneurs: An Introduction.” CES Working Paper \#15-40R. May. ftp://ftp2.census.gov/ces/wp/2015/CES-WP-15-40R.pdf (accessed January 31, 2017).

Fort, Teresa. 2017. “Technology and Production Fragmentation: Domestic Versus Foreign Sourcing”, Review of Economic Studies, 84, 650-687.

Government Accountability Office. 2007. A Strategy for Reducing the Gap Should Include Options for Addressing Sole Proprietor Noncompliance, GAO-07-1014, Report to the Committee on Finance, U.S. Senate.

Goldschmidt, Deborah and Johannes F. Schmieder, 2017. "The Rise of Domestic Outsourcing and the Evolution of the German Wage Structure,” Quarterly Journal of Economics, 132(3), 1165-1217.

Hall, Jonathan and Alan Krueger. 2018. "An Analysis of the Labor Market for Uber's Driver-Partners in the United States,” ILR Review, 71(3), 705-732.

Harris, Seth D. and Alan B. Krueger. 2015. “A Proposal for Modernizing Labor Laws for Twenty-FirstCentury Work: The ‘Independent Worker’,” Hamilton Project Discussion Paper 2015-10, December.

Hipple, Steven F. and Laurel A. Hammond. 2016. "Self-Employment in the United States," Bureau of Labor Statistics, Spotlight on Statistics, March. https://www.bls.gov/spotlight/2016/self- employment-inthe-united-states/home.htm (accessed January 31, 2017).

Houseman, Susan. 2007. "Outsourcing, Offshoring and Productivity Measurement in United States Manufacturing,” International Labour Review, 146(1-2), 61-80.

Hurst, Erik and Benjamin Wild Pugsley. 2011. “What Do Small Businesses Do?” Brooking Papers on Economic Activity, Fall 2011, 73-118.

Hyatt, Henry R. and James R. Spletzer. 2017. “The Recent Decline in Single Quarter Jobs.” Labour Economics, forthcoming.

Jackson, Emilie, Adam Looney, and Shanthi Ramnath. 2017. "The Rise of Alternative Work Arrangements: Evidence and Implications for Tax Filing and Benefit Coverage,” Office of Tax Analysis Working Paper 114. January.

Katz, Lawrence F. 2018. “Discussion of 'Driving the Gig Economy,' by Abraham, Haltiwanger, Sandusky and Spletzer,” presentation at the National Bureau of Economic Research Summer Institute meetings. July. 
Katz, Lawrence F. and Alan B. Krueger. 2016. "The Rise and Nature of Alternative Work Arrangements in the United States, 1995-2015,” unpublished working paper.

Koustas, Dmitri. 2018. "Consumption Insurance and Multiple Jobs: Evidence from Rideshare Drivers,” unpublished working paper.

Leberstein, Sarah. 2012. "Independent Contractor Misclassification Imposes Huge Costs on Workers and Federal and State Treasuries,” National Employment Law Project. August.

Lombardi, Britton and Yukako Ono. 2010. "Professional Employer Organizations: Who Are They, Who Uses Them, and Why Should We Care?” Center for Economic Studies Working Paper CES 10-22.

Manyika, James, Susan Lund, Jacques Bughin, Kelsey Robinson, Jan Mischke, and Deepa Mahajan.2016. "Independent work: Choice, necessity, and the gig economy.” McKinsey Global Institute. October. Available at http://www.mckinsey.com/global-themes/employment-and- growth/independent-workchoice-necessity-and-the-gig-economy (accessed January 31, 2017).

National Academies Press. 2017. Information Technology and the Workforce: Automation, Augmentation and Transformation, Washington, DC.

Polivka, Anne E. 1996a. “Contingent and alternative work arrangements, defined,” Monthly Labor Review, October, 3-9.

Polivka, Anne E. 199b. “A profile of contingent workers,” Monthly Labor Review, October, 10-21.

Pollard, Michael and Matthew D. Baird. 2017. The RAND American Life Panel: Technical Description. Rand Corporation Report.

Robles, Barbara and Marysol McGee. 2016. "Exploring Online and Offline Informal Work: Findings from the Enterprising and Informal Work Activities (EIWA) Survey,” Finance and Economics Discussion Series 2016-089. Washington: Board of Governors of the Federal Reserve System.

Slemrod, Joel, Brett Collins, Jeffrey Hoopes, Daniel Reck, and Michael Sebastiani, 2017. "Does Credit- card Information Reporting Improve Small-business Tax Compliance?,” Journal of Public Economics, 149, 1-19.

Slemrod, Joel and Jon Bakija. 2008. Taxing Ourselves: A Citizen’s Guide to the Debate over Taxes, Fourth Edition, Cambridge, Massachusetts: MIT Press.

Weil, David. 2014. The Fissured Workplace, Cambridge MA: Harvard University Press. 


\section{Data Appendix}

Household survey data on self-employment. The Current Population Survey (CPS) is a monthly household survey with a sample that represents the civilian population of the United States. The basic monthly CPS questionnaire collects relatively rich information on the characteristics of all members of selected households age 16 and older, including their age, sex, race, ethnicity, nativity, disability status, and education. The monthly instrument also contains questions to determine whether household members were employed during the survey reference week (normally the week that includes the $12^{\text {th }}$ of the month) and, if so, whether each person had more than one job during that week. For those categorized as employed, the CPS asks about the occupation and industry of the main job, hours on the main job, and combined hours on any other jobs. Additional questions are asked that allow a person's status on their main job to be categorized as wage and salary, self-employed with an incorporated business, self-employed with an unincorporated business, or unpaid family worker. In published Bureau of Labor Statistics (BLS) statistical series on selfemployment based on the monthly data, individuals who operate an incorporated business are categorized as wage and salary workers rather than as self-employed, but both the incorporated and the unincorporated selfemployed can be identified in the underlying microdata. Information on the industry, occupation and type of employment for any reported second jobs is collected for a quarter of the sample-those in the so-called outgoing rotation groups — and is not collected at all for any additional jobs. Finally, for the quarter of the sample in the outgoing rotation groups, the monthly CPS collects information on earnings on the main job. Except for the information on disability status, which has been collected since June 2008, all of these data are available on a consistent basis beginning in 1994, the year of the most recent major CPS redesign.

The Annual Social and Economic (ASEC) supplement that is administered each spring to CPS households collects information for the preceding calendar year. Respondents are asked about the number of weeks during the year worked by each member of the CPS household, the number of jobs each household member held during the year, and the industry, occupation and type of the longest job. ${ }^{19}$ These data allow

\footnotetext{
${ }^{19}$ Individuals who hold two jobs simultaneously rather than in sequence are instructed to report holding just one job.
} 
the longest job held during the year to be categorized as wage and salary, self-employed incorporated, selfemployed unincorporated or unpaid. In addition, the CPS-ASEC supplement contains questions about wage and salary income and business income received during the year, whether from the longest job or from other jobs. The data on business income from employment other than the longest job combine profits from incorporated and unincorporated self-employment. We use the responses to these questions to construct a self-employment indicator that equals one if a person is classified as self-employed unincorporated on their longest job and has positive self-employment earnings or, if the longest job was not unincorporated selfemployment, has positive self-employment income on a job other than the longest job. Data from the CPSASEC supplement are available beginning in 1962.

Although we do not know whether self-employment earnings on a job other than the longest job are from incorporated or unincorporated self-employment, we expect most self-employment outside of the longest job to be unincorporated self-employment. We cannot look at this directly, but have looked at data from the monthly CPS that, for those in the outgoing rotation group, captures class of worker both for the main job and for any second job. Using these data, we identified people who were self-employed unincorporated on their main job or were either self-employed incorporated or self-employed unincorporated on a second job. Consistent with our prior that secondary incorporated self-employment is relatively rare, only about 2 to 3 percent of those categorized as self-employed according to this definition were so classified because of a second job that was reported to be incorporated self-employment.

The American Community Survey (ACS) is a Census Bureau survey with a very large sample that represents the U.S. civilian population. For each household member age 15 years or older, the ACS asks whether the person worked for pay during the prior seven days ("last week"). For those who are reported to have worked, additional questions collect information about the main job held during the reference weekthe industry and occupation of the work and whether the person was a wage and salary worker, selfemployed with an incorporated business, self-employed with an unincorporated business, or an unpaid family worker. The ACS also requests the total amounts of employee compensation and self-employment income earned by each household member over the prior 12 months. These data could in principle be used to 
construct an earnings-based measure of self-employment activity. Because the questions on the ACS do not ask separately about income from the longest job versus income from other jobs, however, the resulting measure would encompass everyone reporting income from either incorporated or unincorporated selfemployment. ACS estimates of self-employment on the main job last week are available from 2005 through the present. Although some ACS data were collected beginning in 2001, the survey was not fully implemented until 2005 and that is the first year for which published estimates are available.

Tax data on self-employment. The Master Earnings File (MEF) maintained by the Social Security Administration (SSA) is one source of administrative data on self-employment earnings. The MEF includes information on each W-2 a person received for calendar years from 1978 onward, including the earnings reported on the W-2 and the employer from whom those earnings were received, and on the total selfemployment earnings in each of the same years reported on a Schedule SE filed by the taxpayer. A Schedule $\mathrm{SE}$ is required of sole proprietors, general partners and farmers with gross self-employment earnings above a defined threshold that effectively has been set at $\$ 433$ over the period covered by our analysis. More than 85\% of Schedule SE filers are sole proprietors (Jackson, Looney and Ramnath 2016). The MEF records are not public, but an extract called the Detailed Earnings Record (DER) covering all linked CPS-ASEC and SIPP respondents for whom there is a Protected Identification Key (PIK) has been provided to the Census Bureau for specified statistical uses. The latest extract delivered to the Census Bureau for the CPS-ASEC sample contains information on MEF earnings for 1978 through 2012 for individuals in the 1997 through 2013 CPS-ASEC samples, from whom survey information referencing the years 1996 through 2012 was collected.

The Census Bureau's Business Register (BR) is the master business list that the Census Bureau maintains for use as a sample frame for all of its business surveys as well as a source that is tabulated directly to produce a variety of business statistics. The BR is based primarily on administrative data from business income and payroll tax returns. It includes records for both employer and nonemployer businesses. Each record on the file is assigned a detailed industry code. Employer businesses are those with positive payroll in a year while nonemployer businesses are those with qualifying business revenue but no paid employment. As 
stated on the Census Bureau’s website, “most nonemployers are self-employed individuals operating unincorporated businesses (known as sole proprietorships), which may or may not be the owner's principal source of income.” To be included in the nonemployer universe for tabulation, other than in construction, a business must have at least $\$ 1,000$ in gross revenue (in construction, the threshold is at least $\$ 1$ in gross revenue). Businesses with more than some maximum amount of annual revenue are excluded from the nonemployer universe on the grounds that businesses with revenues over the threshold amount are likely to have employees and thus to appear on the list of employer businesses. The upper revenue threshold is determined based on the business's legal form of organization (sole proprietorship, partnership or corporation) and industry. Information about payroll and other business costs also is recorded in the BR. Published data on nonemployers are available beginning in 1997 and statistics broken out by legal form of organization have been produced since 2004 .

The Form 1099-MISC also contains information relevant to assessing trends in self-employment income. This is the tax form used by businesses to report payments of non-employee compensation. Applicable regulations require that a Form 1099-MISC be filed by business payers when non-employee compensation paid to any source equals or exceeds $\$ 600$ over the course of a year; applicable amounts are recorded in Box 7 of the form. One complication is that a Form 1099-MISC may be issued either to an individual (using an SSN) or to a business (using an EIN). Further, the dollar amounts reported on the Form 1099-MISC are gross payments rather than the net amounts earned by the recipient after expenses. Individuals or businesses performing work for a homeowner rather than for a business will not receive a Form 1099-MISC. Staff at the Department of the Treasury have compiled counts of the number of individuals and the number of businesses receiving Form 1099-MISCs that had positive amounts reported in Box 7, Non-employee Compensation, for each year from 2000 through 2012. These counts are available from U.S. Department of the Treasury (2015), but as of this writing have not since been updated.

To calculate a self-employment rate - the share of workers who are self-employed - a measure of the total number of workers is needed to serve as the denominator. The denominators for the monthly CPS and the ACS measures are estimates of the number of people employed during the survey reference week based 
on the same survey. For the two CPS-ASEC measures, the denominator is the estimated number of people with any work activity during the year in question, again based on the same survey. The denominator for all of the measures based on administrative data is the estimated number of people with any employment during the year based on the earnings captured in the DER.

A complication is that we do not have DER data for 2013, 2014 or 2015. For those years, we projected the 2012 DER employment estimate forward using the ratio of annual average employment from the Bureau of Labor Statistics monthly payroll survey (formally, the Current Employment Statistics survey) for the year in question to 2012 annual average payroll survey employment. Over the years from 1996 through 2012, the annual percent change in employment estimated using the DER and the percent change in annual average payroll survey employment have a correlation of 0.89 , and the two series also had a similar mean annual growth rate $(0.72 \%$ for the payroll survey and $0.76 \%$ for the estimate of employment based on the DER). The similarity in the two series’ behavior over the 1996 to 2012 period gives us reasonable confidence that the DER employment values we project for 2013 through 2015 should be approximately correct.

Linked Household Survey-Administrative Data File. Individuals in our linked household surveyadministrative sample were members of a household for which a CPS-ASEC interview was conducted in at least one year between 1997 and 2013. In each case, the reference period for these interviews was the prior calendar year, meaning that information was obtained for the years 1996 through 2012. These CPS-ASEC individuals were linked to $\mathrm{W}-2$ and Schedule SE earnings information provided to the Census Bureau by the Social Security Administration (SSA) in the form of the Detailed Earnings Record or DER, the previouslymentioned extract from the Master Earnings File or MEF. This linking was performed using the Protected Identification Key (PIK), which is a replacement for the SSN.

One complication in creating the linked file is that the PIK is missing for $20 \%$ to $30 \%$ of ASEC respondents, depending on the year. We used propensity score methods to reweight the sample of people for whom we have a PIK so that they represent the population as a whole. For each year, we estimated a regression model in which an indicator for having a PIK was regressed on indicators for age group, gender, 
race, education, marital status, foreign-born status, state of residence, and whether the person reported being employed in the relevant CPS-ASEC. We used the coefficients from this model to calculate each individual's probability of having a PIK and applied a weight adjustment factor equal to the inverse of this probability to the CPS-ASEC estimation weight. Individuals with a PIK were retained in our sample regardless of whether we were able to locate any W-2 or Schedule SE earnings for them in the DER.

The presence of imputed values for self-employment status in the CPS-ASEC creates another complication. These values are imputed for individuals representing approximately $20 \%$ of the population. We have replicated our analysis with all of these cases dropped from the linked sample and the data reweighted using propensity score methods to account for the loss of observations that lack directly reported information on self-employment. Restricting our attention to individuals with directly reported selfemployment status had little effect on the conclusions to be drawn from our analysis.

\section{Reference}

Jackson, Emilie, Adam Looney, and Shanthi Ramnath. 2017. "The Rise of Alternative Work Arrangements: Evidence and Implications for Tax Filing and Benefit Coverage,” Office of Tax Analysis Working Paper 114. January.

U.S. Department of the Treasury. 2015. Letter from Anne Wall, Assistant Secretary for Legislative Affairs, to Senator Mark Warner. October 27. Published in Tax Notes Today: Treasury Tax Correspondence, November 18, 2015. 
Figure 1: Household Survey and Administrative Data Self-employment Rates, 1996-2016

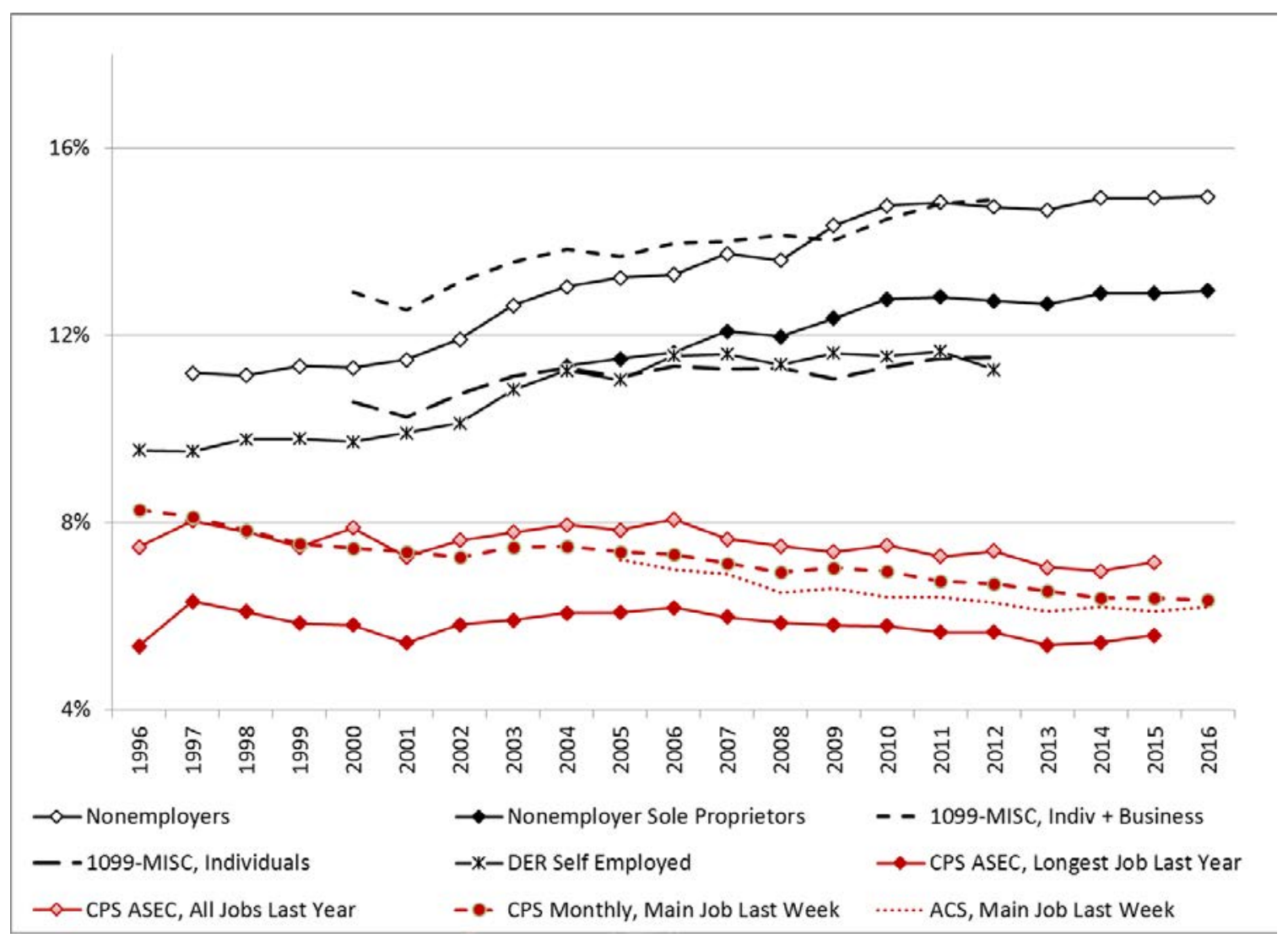

Source: 'Nonemployers' is downloaded from the Census Bureau website.

'Nonemployer Sole Proprietors' is downloaded from the Census Bureau website.

“1099-MISC, Indiv + Business” is from U.S. Department of Treasury (2015).

“1099-MISC, Individuals” is from U.S. Department of Treasury (2015).

"DER Self Employed” is authors' calculations from integrated CPS and DER data.

"CPS ASEC, Longest Job Last Year" is authors' calculations from the public CPS-ASEC file.

“CPS ASEC, All Jobs Last Year” is authors' calculations from the public CPS-ASEC file.

"CPS Monthly, Main Job Last Week' is downloaded from the BLS website.

“ACS, Main Job Last Week” is downloaded from the Census Bureau website. 
Figure 2A: Self-employment in the CPS and the DER

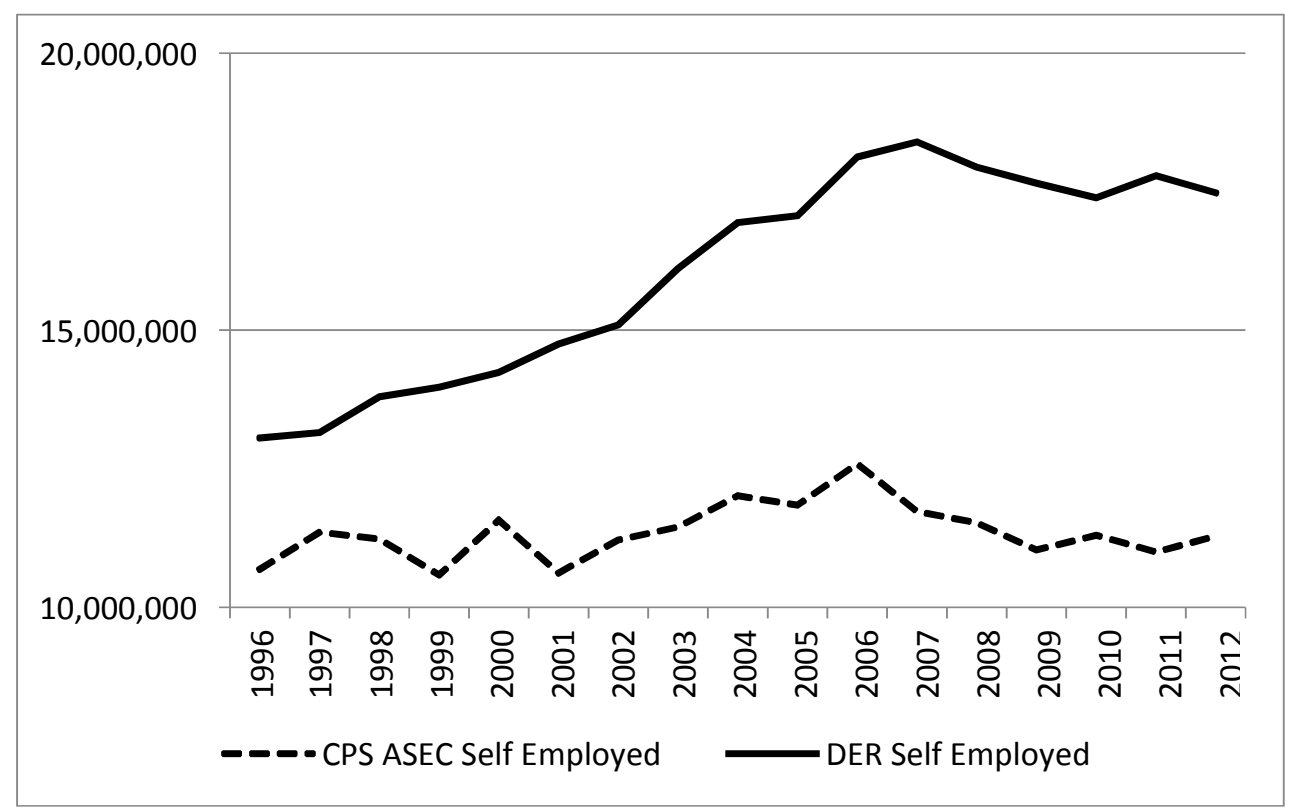

Note: Tabulations by authors from integrated CPS and DER data.

Figure 2B: “Off-Diagonal” Patterns of Self-employment from the CPS and DER

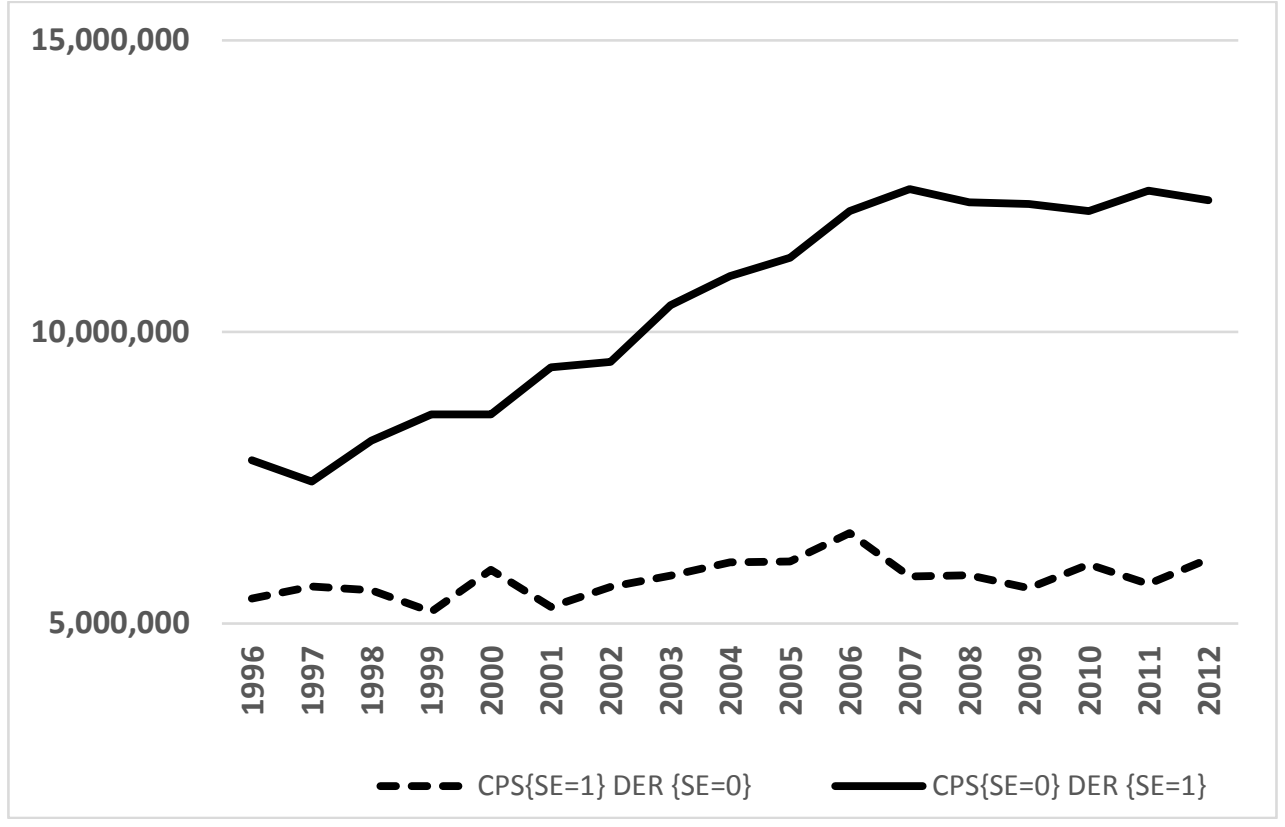

Note: Tabulations by authors from integrated CPS and DER data. The dashed line is the set of individuals who have positive self-employment in the CPS but no self-employment in the DER. The solid line is the set of individuals who have positive self-employment in the DER but no self-employment in the CPS. 
Figure 3A: Decomposing the Off-Diagonal of DER (SE=1), CPS (SE=0)

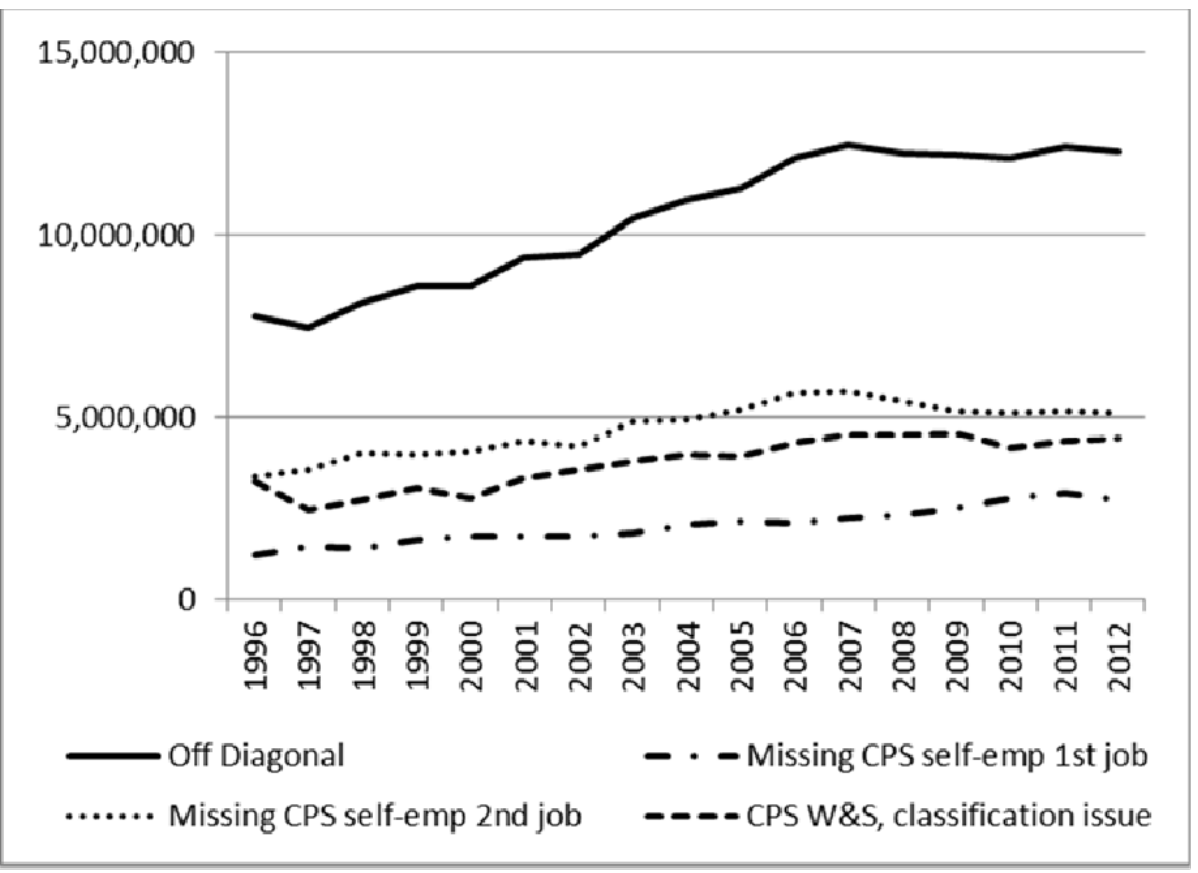

Figure 3B: Decomposing the Off-Diagonal of DER (SE=0), CPS (SE=1)

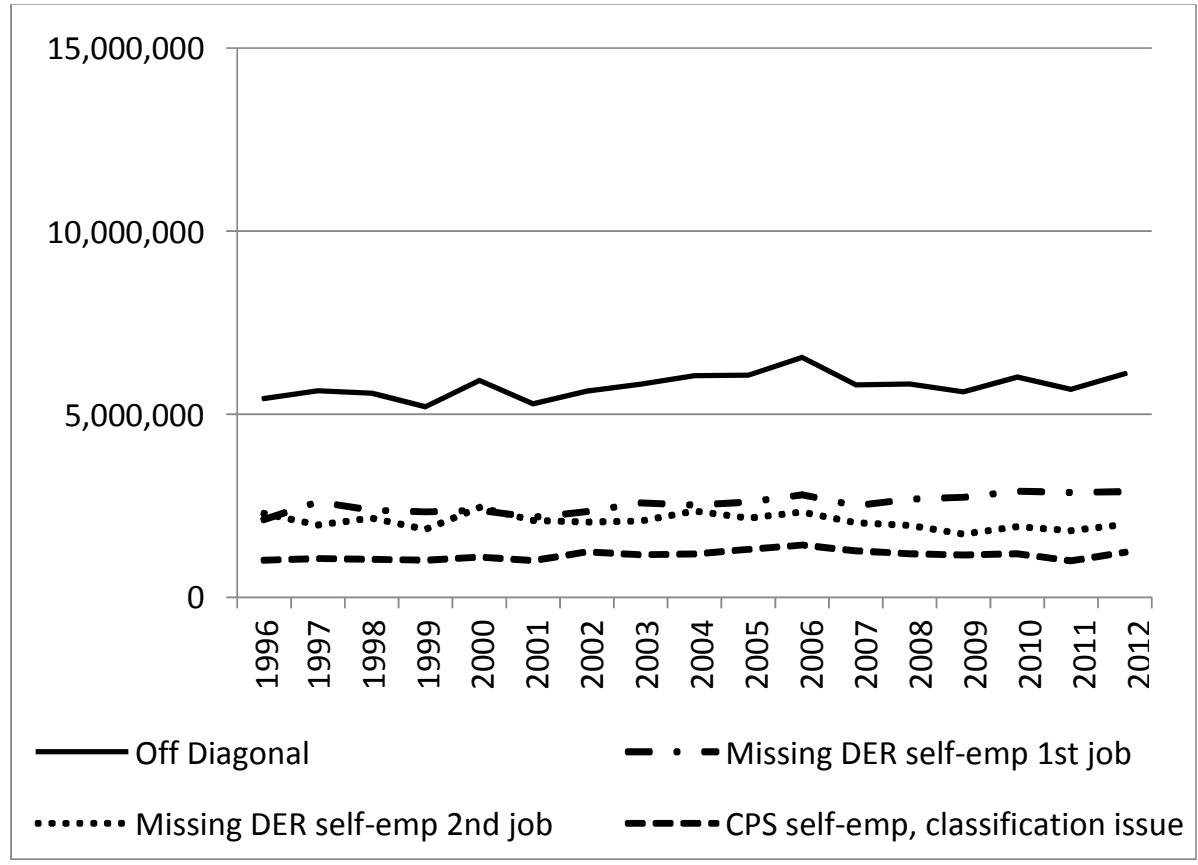

Source: Tabulations by authors from integrated CPS and DER data. 
Table 1: Work Arrangement Types and Characteristics

\begin{tabular}{|c|c|c|c|c|c|c|c|c|c|}
\hline \multirow[b]{2}{*}{ Work arrangement type } & \multicolumn{5}{|c|}{ Work Arrangement Characteristic } & \multicolumn{3}{|c|}{ How Work Arrangement Reported } & \multirow[b]{2}{*}{ Gig worker? } \\
\hline & $\begin{array}{c}\text { Paid wage or } \\
\text { salary }\end{array}$ & $\begin{array}{l}\text { Implicit or } \\
\text { explicit } \\
\text { contract for } \\
\text { continuing } \\
\text { relationship }\end{array}$ & $\begin{array}{c}\text { Predictable } \\
\text { work schedule }\end{array}$ & $\begin{array}{c}\text { Predictable } \\
\text { earnings } \\
\text { when } \\
\text { working } \\
\end{array}$ & $\begin{array}{c}\text { Work } \\
\text { supervised by } \\
\text { firm paying } \\
\text { salary } \\
\end{array}$ & $\begin{array}{l}\text { Classified as } \\
\text { self-employed } \\
\text { in HH surveys }\end{array}$ & $\begin{array}{l}\text { Information } \\
\text { return on } \\
\text { which payer } \\
\text { may report } \\
\text { earnings } \\
{[1]}\end{array}$ & $\begin{array}{c}\text { Tax schedules } \\
\text { attached to Form } \\
1040 \text { for reporting } \\
\text { earnings to IRS } \\
\text { [2] }\end{array}$ & \\
\hline \multicolumn{10}{|l|}{ Employee } \\
\hline Traditional employee & Yes & Some & Yes & Yes & Yes & No & W2 & -- & No \\
\hline On-call/varying schedule worker & Yes & Some & No & Yes & Yes & No & W2 & -- & No \\
\hline Direct-hire temporary worker & Yes & No & Yes & Yes & Yes & No & W2 & -- & No \\
\hline \multicolumn{10}{|l|}{ Contract company workers } \\
\hline Temporary help agency worker & Yes & Some & Yes & Yes & No & No & W2 & -- & No \\
\hline PEO worker & Yes & Some & Yes & Yes & No & No & W2 & -- & No \\
\hline Other contract company worker & Yes & Some & Yes & Yes & No & No & W2 & -- & No \\
\hline \multicolumn{10}{|l|}{$\begin{array}{l}\text { Self-employed } \\
\text { Business owners }\end{array}$} \\
\hline & & & & & & & $\mathrm{W} 2, \mathrm{~K} 1$ or & & \\
\hline Incorporated business owner & Some & Some & Yes & Some & -- & Inc. SE & 1099 & Sched E & No \\
\hline Partner in a partnership & No & Some & Yes & Some & -- & Uninc. SE & K1 & Sched E, SE & No \\
\hline Unincorporated sole proprietor & No & Some & Yes & Some & -- & Uninc. SE & 1099 & Sched C, SE & No \\
\hline Independent contractor/freelancer & No & No & No & No & -- & Uninc. SE & 1099 & Sched C, SE & Yes \\
\hline Day laborer & No & No & No & No & -- & Uninc. SE & 1099 & Sched C, SE & Yes \\
\hline On-demand/platform worker & No & No & No & No & -- & Uninc. SE & 1099 & Sched C, SE & Yes \\
\hline
\end{tabular}

[1] Information returns are required to be filed with the IRS only by certain types of payers and only for payments that exceed certain thresholds. Depending on the arrangements under which they work, those receiving non-employee compensation could receive a 1099-MISC or, since 2011, possibly a 1099-K.

[2] Schedule E is used to report S-Corporation profits and distributions of patnership income. Some of the latter may be subject to self-employment tax. Unincorporated farm operators are required to file a Schedule $\mathrm{F}$ rather than a Schedule $\mathrm{C}$. Individuals with incomes that are sufficiently low may not be required to file an income tax return. 
Table 2: Cross-Tabulation of Self-Employment Status in the CPS and the DER, 1996-2012

Not self-employed

in DER

Self-employed in DER Total

Not self-employed in CPS

$\begin{array}{lccc}\text { Number } & 202,311,037 & 10,459,170 & 212,770,208 \\ \text { Row Share } & 95.1 \% & 4.9 \% & 100.0 \% \\ \text { Column Share } & 97.2 \% & 65.4 \% & 95.0 \%\end{array}$

Self-employed in CPS

Number

$5,776,887$

$5,531,764$

$11,308,651$

Row Share

$51.1 \%$

$48.9 \%$

$100.0 \%$

Column Share

$2.8 \%$

$34.6 \%$

$5.0 \%$

$\underline{\text { Total }}$

$\begin{array}{lc}\text { Number } & 208,087,924 \\ \text { Row Share } & 92.9 \% \\ \text { Column share } & 100.0 \%\end{array}$

$15,990,935$
$7.1 \%$
$100.0 \%$

$224,078,859$

$100.0 \%$

$100.0 \%$

Note: Weighted tabulations of linked CPS-DER data file described in the Data Appendix. Numbers reported are as a share of the population age 16 plus. Data for all years 1996-2012 pooled. 
Table 3: Accounting for Growth in Discrepancy between CPS-ASEC and DER

Self-Employment Estimates, 1996-97 to 2011-12

Percent of Growth

in Discrepancy

Explained

$\operatorname{DER}\{\mathrm{SE}=1\} / \mathrm{CPS}-\mathrm{ASEC}\{\mathrm{SE}=0\}$

1) No CPS employment

$34.5 \%$

2) Self-employment second job not reported in CPS

$38.4 \%$

3) CPS job misreported as wage and salary

$35.2 \%$

CPS-ASEC $\{S E=1\} / D E R\{S E=0\}$

4) No DER employment

$-11.6 \%$

5) Self-employment second job not reported in DER

$5.2 \%$

6) CPS job misreported as self-employment

$-1.8 \%$ 
Table 4: Estimates of the Prevalence of Selected Work Arrangements on Main Job (percent of all workers)

\begin{tabular}{|c|c|c|c|c|}
\hline \multirow[b]{2}{*}{ Source } & \multirow[b]{2}{*}{$\begin{array}{r}\text { Independent } \\
\text { Contractors }\end{array}$} & \multicolumn{3}{|c|}{ Temporary } \\
\hline & & $\begin{array}{r}\text { On-Call } \\
\text { Workers }\end{array}$ & $\begin{array}{r}\text { Help Service } \\
\text { Workers }\end{array}$ & $\begin{array}{r}\text { Contract Firm } \\
\text { Employees }\end{array}$ \\
\hline \multicolumn{5}{|c|}{$\begin{array}{l}\text { Contingent Worker Supplement, } \\
\text { Current Population Survey, BLS } \\
\text { estimates }\end{array}$} \\
\hline 1995 & 6.7 & 1.7 & 1.0 & 0.5 \\
\hline 1997 & 6.7 & 1.6 & 1.0 & 0.6 \\
\hline 1999 & 6.3 & 1.5 & 0.9 & 0.6 \\
\hline 2001 & 6.4 & 1.6 & 0.9 & 0.5 \\
\hline 2005 & 7.4 & 1.8 & 0.9 & 0.6 \\
\hline 2017 & 6.9 & 1.7 & 0.9 & 0.6 \\
\hline \multicolumn{5}{|c|}{ Quality of Worklife Survey, } \\
\hline \multicolumn{5}{|c|}{ General Social Survey $^{\mathrm{a}}$} \\
\hline 2002 & 13.9 & 2.1 & 0.7 & 2.5 \\
\hline 2006 & 13.7 & 2.6 & 1.0 & 3.7 \\
\hline 2010 & 13.3 & 3.7 & 1.4 & 3.1 \\
\hline 2014 & 14.1 & 3.1 & 0.5 & 2.7 \\
\hline
\end{tabular}

${ }^{a}$ In estimates based on the Quality of Worklife Survey, the first response option is "work as an independent contractor, consultant or freelance worker"; the second is "on call, and work only when called to work"; the third is "paid by a temporary agency"; and the fourth is "work for a contractor who provides workers and services to others under contract." 
Table 5: Employment and Multiple Job Holding Rates With and Without Probes for Informal Employment

\begin{tabular}{|c|c|c|c|c|c|c|}
\hline \multirow[b]{2}{*}{ Estimate } & \multicolumn{3}{|c|}{ Response for Self } & \multicolumn{3}{|c|}{ Response for Other Household Member } \\
\hline & $\begin{array}{c}\text { Global } \\
\text { Informal } \\
\text { Employment } \\
\text { Question } \\
\end{array}$ & $\begin{array}{l}\text { Detailed } \\
\text { Informal } \\
\text { Employment } \\
\text { Question } \\
\end{array}$ & $\begin{array}{c}\text { Detailed Minus } \\
\text { Global } \\
\text { Difference } \\
\end{array}$ & $\begin{array}{c}\text { Global } \\
\text { Informal } \\
\text { Employment } \\
\text { Question } \\
\end{array}$ & $\begin{array}{l}\text { Detailed } \\
\text { Informal } \\
\text { Employment } \\
\text { Question } \\
\end{array}$ & $\begin{array}{c}\text { Detailed Minus } \\
\text { Global } \\
\text { Difference } \\
\end{array}$ \\
\hline \multicolumn{7}{|l|}{ Employment rate (percent) } \\
\hline CPS questions only & 94.7 & 94.7 & 0.1 & 69.8 & 69.7 & 0.0 \\
\hline CPS plus additional questions & 96.9 & 98.1 & $1.2^{*}$ & 73.5 & 76.4 & 2.9 \\
\hline Difference & $2.3 * *$ & $3.4 * *$ & 1.2 & $3.7 * *$ & $6.7 * *$ & $3.0 * *$ \\
\hline Sample size & 1,364 & 1,340 & -- & 1,128 & 1,107 & -- \\
\hline \multicolumn{7}{|c|}{$\begin{array}{l}\text { Multiple job-holding rate among CPS } \\
\text { employed (percent) }\end{array}$} \\
\hline CPS questions only & 32.0 & 31.8 & -0.2 & 10.6 & 10.0 & -0.6 \\
\hline CPS plus additional questions & 55.9 & 56.5 & 0.6 & 13.5 & 21.2 & $7.8 * *$ \\
\hline Difference & $23.9 * *$ & $24.7 * *$ & 0.7 & $2.9 * *$ & $11.3 * *$ & $8.4 * *$ \\
\hline Sample size & 1,291 & 1,269 & -- & 787 & 772 & -- \\
\hline
\end{tabular}

* Significant at 0.05 level. ** Significant at 0.01 level.

Source: Abraham and Amaya (2018) 